\title{
Characterization of cooling loads in the wine industry and novel seasonal indicator for reliable assessment of energy saving through retrofit of chillers
}

\author{
P. Catrini, D. Panno, F. Cardona, A. Piacentino* \\ Department of Engineering, University of Palermo \\ Viale delle Scienze, Building n. 9, 90128, Palermo (Italy) \\ Email: piacentino@dream.unipa.it
}

\begin{abstract}
The food sector is a major consumer of energy and growing efforts are being made in the search for solutions that will guarantee the efficient and sustainable use of energy resources. Among the different sectors, wineries are attracting particular interest due to the continuous growth of the global market and production. Surveys conducted in the winemaking sector have highlighted the importance of performing accurate energy audits and have identified the installation of efficient refrigeration systems as a promising solution in a variety of cases. Unfortunately, the savings achievable by efficient cooling technologies are often estimated using simplified approaches which do not take into consideration the actual operating conditions of the equipment typically variable on seasonal and daily bases. In this paper a novel bottom-up procedure is presented, aimed at developing reliable profiles for refrigeration and air-conditioning loads and at assessing the extent to which more efficient chilling units could contribute to reducing electricity consumption. The use of standard Seasonal Energy Efficiency Ratios is critically discussed and a novel customized indicator is proposed. The method is applied to a medium-scale winery producing still red and white wines and sparkling wines, for which only aggregated energy consumption data are available. After deriving detailed load profiles, it is proven that the use of standard seasonal indicators leads to $56.85 \%$ and $83.87 \%$ overestimation of potential energy savings, respectively, for low and medium temperature cooling energy uses, confirming the importance of adopting seasonal indicators customized on the actual operating conditions of chillers.
\end{abstract}

\section{Keywords}

Energy saving, wineries, energy audit, cooling load, industrial chillers, seasonal energy efficiency ratio

\section{Introduction}

Energy consumption in the food sector accounted for approximately 17\% of the EU's gross energy consumption in 2013, $28 \%$ of this total energy use being related to a particular phase of the food life cycle that is industrial processing [1]. Several studies in recent years have investigated the potential measures for energy saving in food processing. Pantaleo et al. analysed the integration of cogeneration and intermittent waste-heat recovery in the coffee-roasting industry, comparing the viability of microturbines and ORC systems [2]. Wu et al. proposed the combined use of life cycle assessment and virtual cold chains to identify environmental trade-offs in a fresh fruit cold chain [3]. Zhang et al. [4] studied the role of potential investors in financing renewable energy systems, focusing the attention on the milk production chain and the possible contribution of photovoltaic water pumping to a more sustainable milk product. A paper by Seck et al. [5] discussed the contribution that energy-saving certificates could offer to the viability of waste heat recovery 
strategies based on heat pumps in the food and drink industry. Despite the great research efforts, large margins for improvement of food processing plants still exist.

\subsection{Sustainability issues and assessment in wineries}

Among the food industries, the winemaking sector has been attracting a growing interest due to the high energy intensity of wineries and the consequent concern about their impacts in terms of energy and fresh-water consumption, greenhouse gas emissions and production of pollutant residues. In order to assess the sustainability of wine industries, a first step consists of identifying appropriate impact indicators and benchmarks. A study by Martins et al. [6] identified a set of indicators covering the environmental and economic levels of "sustainability". The study compared the sustainability of two Portuguese wines, and a lifecycle analysis allowed the identification of the "winemaking" phase as the most relevant for energy intensity, while the "bottling" phase resulted as the highest contributor to carbon emissions indicator. Gilinsky et al. [7] carried out a comprehensive survey about sustainability in the global wine industry, referring to the established practices in several countries with a strong tradition in wine production (France, Italy, Spain, California, Argentina and New Zealand). The solutions adopted to increase awareness on the sustainability issues and the development of metrics for benchmarking sustainability and justifying new investments were compared. The identification of suitable indicators was found to be crucial in assessing the wineries' progress toward sustainability. In this respect, Merli et al. [8] compared the set of indicators adopted in the framework of some wine industry programmes, i.e. the Italian "VIVA sustainable wine" project, the "Californian Sustainable Winegrowing Alliance" (CSWA) and the "Environmental Management System" (EMS) defined by the European Regulation on EcoManagement and Audit Scheme (EMAS). It was observed that both the CSWA and EMAS indicators focus only on the environmental level of sustainability, while the VIVA indicators also account for the economic and social implications of this concept. Another study by Flores [9] proposed a cross-country analysis of a wine sustainability framework, pointing out that other systems like Sustainable Wine South Africa (SWSA) and Sustainable Winegrowing New Zealand (SWNZ) also account for (i) economic sustainability of structures and territories, (ii) product quality and safety and (iii) heritage, historic, cultural and aesthetic aspects. The above references clearly reveal the need for a lifecycle perspective on the road to sustainability; indeed, the winery and the production process of wine from grapes are often mainly responsible for the total impact, yet other phases also make a non-negligible contribution. Cholette and Venkat [10] studied the energy and carbon intensity of wine distribution using a web-based tool to calculate the energy consumption and carbon emissions associated with each transportation link and storage option. The results confirmed that extremely different energy and emissions profiles can be obtained, depending on the adopted supply chain configuration.

\subsection{Energy valorization of residue materials}

The exploitation of the energy potential of the residues from the wine production chain has also attracted a great deal of interest. Filho et al. [11] analyzed the biogas and methane generation potential from wastes in a vineyard in Brazil. The grapes showed a significantly higher yield in comparison with other wastes, and the heat recovery potential achieved through anaerobic digestion resulted as being highly sensitive to the percentage of each biomass in the residues. FernándezPuratinch et al. [12] characterized the chip pruning of five different wineries, analyzing their calorific value and ash content. The wood biomass was supposed to replace the pine pellets used in 
the boilers of several vineyards, and a significant reduction in $\mathrm{CO} 2$ emissions resulted. A detailed analysis of the characteristics of the residues from the wine production chain was performed by Toscano et al. [13], with the aim of assessing the potential for industrial energy recovery. The heterogeneous nature of these residues, composed of marcs, stalks, peels (i.e. grape skins) and grapeseeds, required a complex physical-chemical characterization, allowing the calculation of several parameters such as moisture content, ash, and high and low heat values of a number of chemical species. The gross energy content from the recovery of residual biomass from a hectare of grapevine was approximately equal to 19 GJ. In a study by Bacenetti [14], energetic valorization of pruning residues was assessed as an option to produce heat and cold to supply the requirements of a winemaking facility. The adopted lifecycle perspective allowed for a thorough comparison between alternative valorization scenarios.

Along the route towards sustainability, efficient use of energy and supply by renewable or lowimpact energy sources are the most promising solutions, due to the high energy consumption per hectolitre (hl) of bottled wine.

\subsection{Energy uses in the winemaking process}

Large efforts have been devoted to the characterization of energy use in wineries, which is a complex task because the process and equipment used vary widely and depend on a number of factors. A large-scale cooperative project [15], namely "TESLA - Transferring Energy Save Laid on Agroindustry", identified some average energy consumption figures of wineries, based on extensive data gathering in wineries located in Spain, France, Portugal and Italy. It was estimated that a winery with a $30,000 \mathrm{hl} / \mathrm{year}$ capacity consumes on average $11 \mathrm{kWh}$ of electricity and $1 \mathrm{kWh}$ of thermal energy per hectolitre of bottled wine. The above figure varies with the production capacity, with specific consumption of electricity ranging between $4 \mathrm{kWh} / \mathrm{hl}$ in big facilities (wine production above 50,000 hl/year) and $16 \mathrm{kWh} / \mathrm{hl}$ in smaller ones (production lower than 25,000 hl/year). In a study by Smyth and Nesbitt [16], a review of energy use in the English and Welsh wine industry is proposed, based on data collected through energy audits in 21 wineries. The analysis assessed an average of $55.7 \mathrm{kWh} / \mathrm{hl}$ energy consumption, with values ranging between 4.0 and $206.5 \mathrm{kWh} / \mathrm{hl}$. These values, much higher than those presented in the TESLA project, are influenced by the considerable disparity between the various winemaking facilities. Looking at the energy uses in wineries in more detail, several distributions of electricity consumption among specific processes, equipment and appliances have been presented so far. In most of these studies [16-17], refrigeration at various stages of the wine-making process and space heating and cooling represent the highest share of energy consumption, accounting for 40-60\% of total electricity use [18]. Sterilization/cleaning, packaging and bottling represent another relevant energy demand, accounting for $10-25 \%$ of total energy consumption. The relevance of other energy uses such as pumping-fan-drivers (2-35\% of total electricity use), lighting (14-22\% of total consumption) and compressed air services (3-10\% of total energy use) is highly variable within the winemaking facility, depending on the logistic and operational features of the plant. As recognized in [17], the first step toward improvement consists of knowing "where" and "when" the winery uses energy, which requires performing an accurate energy audit of the wine-making facility. The aforementioned surveys have pointed out that awareness about energy use in wineries is often insufficient among plant owners: in most cases, data concerning historical energy consumption essentially consist of energy bills, and operators only have a rough idea about the share of total 
consumption related to each subprocess. Conversely, an accurate energy audit provides a detailed picture of energy use, contributing to the identification of most promising routes for improvement. In a study by Vela et al. [19], the energy audit carried out for a large winery allowed the authors to identify 296 electrical devices grouped into 63 different types, and to assess the potential savings achievable through nine energy efficiency measures. Malvoni et al. proposed a detailed energy audit for an Italian winery [20], identifying the share of total electricity consumption related to each phase of the process and assessing the viability of possible interventions such as improvements in thermal insulation of storage tanks. Garn assessed the benefits of energy auditing for a winery [21] through an interesting survey of available tools for benchmarking energy use in wineries.

Among these tools the "Benchmarking and Energy and Water Savings Tool" (BEST), an interactive software tool distributed to wineries in California, represents the best example [22]. This tool models the energy use at a winery at seven main process steps of winemaking, requiring basic input such as the amounts of grapes received, juice fermented and wine undergoing malolactic fermentation and cold stabilization on an annual basis, as well as the amount of wine produced and bottled in the plant. Reasonable figures for energy and water consumption are calculated, which serve as benchmarks for a winery to assess its margins for improvement.

\subsection{Potential of renewable energy supply in wineries}

After completing an energy audit, solutions for sustainable energy use and supply must be identified. One of the most exploited strategies is aimed at supplying a share of the total energy requests by using renewable energy sources, potentially from solar systems since there are often large ground and/or roof areas where these plants can be installed. Gómez-Lorente et al. [23] investigated the feasibility of using solar energy in Spanish wineries, assessing the potential for a reduction in electricity costs ranging from $4 \%$ to $36 \%$. Jia et al. analyzed the main challenges for the effective exploitation of solar energy in the winemaking industry [24]. The study is based on a worldwide survey of energy use in wineries, focusing on monthly profiles of energy requests and on the mismatch with temporal profiles of solar source availability. The potential for the use of Solar Thermal Collectors resulted much lower than for PhotoVoltaic (PV) systems, due to the prevalence of electrical loads compared to thermal ones. Carroquino et al. [25] proposed a more complex system based on the combined production of electricity and hydrogen from solar energy to supply the wastewater treatment plant of a winery and the irrigation system of a vineyard. The study demonstrated the feasibility of an isolated PV plant that eliminates both local power generation from diesel oil and the need for aerial power lines. In a recent survey by García-Casarejos et al. [26], the attitude of the wine sector toward renewables for reducing Greenhouse Gas Emissions (GHG) was discussed, pointing out that a large percentage of Spanish wineries are willing to incorporate renewable sources into their supply strategy, but that further instruments to support the financing of investments are needed.

\subsection{Reducing energy intensity of bottled wine by improving energy efficiency}

A second main strategy towards sustainability in wineries is aimed at decreasing the energy consumption per unit product by increasing the efficiency of the phases in the winemaking process where most of the energy is consumed. In a paper by Genc et al. [27], an exergy analysis of the red wine production process was presented, accounting for the physical and chemical exergy of all the material flows. Depending on whether or not the exergy of waste was accounted for, the pneumatic 
press and the open fermenter resulted as being the components with the highest exergy destruction. especially in the production of high-quality wines where reduction of waste streams are difficult to achieve. The possibility of decreasing the energy demand in wine production using cold prefermentation was investigated by Celorrio et al. [28]. In this study, the energy analysis of the maceration phase covered both the requests for initial abatement of product temperature and the loads to maintain it within established limits. The results showed that a simple installation based on wind energy and photovoltaic solar energy can reduce the energy purchase for cold prefermentation by $30 \%$. Another study by the same research group developed a method for the reduction of energy demand during cold stabilisation in the wine industry [29], achieving savings of up to $75 \%$ for cold stabilisation cycles of 7 days. The approach is based on the simultaneous implementation of several measures, such as the improvement in thermal insulation of the tanks, the pre-cooling of incoming product by heat exchange with the stabilized product, the reduction in the temperature of the area hosting the tanks, the replacement of the chiller with another achieving a higher Energy Efficiency Ratio (EER) and the adoption of multiple set-points through a sequential control strategy at night-time. Optimization of cooling load based chiller sequencing control was proven to guarantee minimum energy consumption in multiple-chiller plants, allowing the detection of trade-offs among the energy consumption of chillers and auxiliaries such as cooling towers and pumps [30]. In the same research line, Wang et al. proposed an online control strategy for multiplechiller plants based on a near-optimal performance map aimed at maximizing energy saving [31]. A different approach to reducing cooling energy consumption was proposed by Schenk et al. [32], who focused on the effects of the temperature control strategy during the fermentation process. An Economic Nonlinear Model Predictive Control was adopted to minimize the energy consumption for cooling during fermentation while ensuring the quality of the wine and avoiding the formation of off-flavors. Mazarrón et al. investigated the feasibility of using the thermal inertia of the ground that surrounds underground cellars where wine undergoes storage/aging, so as to control the temperature and reduce the loads for space cooling [33]. Another promising research field concerns the potential of cold energy storage for reducing the energy load for space cooling in warehouses. Zhu et al. [34] proposed a techno-economic feasibility analysis for a system to be installed in a warehouse used to store fresh food at $0-4{ }^{\circ} \mathrm{C}$. Simulations performed by a transient simulation software confirmed that the cold energy storage allowed shifting electricity consumption from peak to off-peak hours, resulting in attractively short payback periods. A study by Li et al. reviewed the positive cold energy storage technology based on Phase Change Materials (PCM) for airconditioning applications [35]; the great potential of using materials with phase change in the range of $7-14^{\circ} \mathrm{C}$ was confirmed, yet materials observing phase change at lower temperatures for processcooling were not examined in this paper. Mađerić et al. investigated the energy efficiency of a beverage cooler with latent heat storage, proving that replacement of thermostatic control with an ice bank relay allowed for energy-saving [36].

\subsection{Purpose and novelty of the study}

The above literature review shows that energy efficiency in wineries is a hot research topic and that most of the potential improvements are related to reducing the energy supply to the process. Since the energy consumption for cooling and air-conditioning in wineries accounts for the largest share of energy consumption, in this paper (i) the attainment of reliable cooling load profiles and (ii) the 
potential savings achievable by retrofitting the existing chillers (when obsolete) with more modern

and efficient machines are discussed.

With regard to the first aspect (i), worthy of investigation due to the current knowledge gap regarding the energy audit of cooling uses in the wine industry, the methodological contribution of this paper lies in a novel bottom-up procedure aimed at developing cooling load profiles in wineries. The proposed approach is suitable for wineries where only aggregated energy consumption data are available (this is a very common case, as already mentioned) and no Energy Management Systems nor monitoring equipment are installed to extract such data.

With regard to the second aspect (ii), the novelty of the paper lies in the adoption of a comprehensive approach to quantifying the potential savings from chiller retrofit, based on accurate consideration of the actual operating conditions of chillers and on a more detailed modelling of their performance. While the literature review reported that several studies focused on complex configurations like multiple-chiller plants, in most wineries a single chiller is installed to supply all the cooling loads requiring the same process-fluid temperature. In such cases, analyses aimed at assessing the potential energy savings often use a single value of EER or seasonal performance indicators (such as the Seasonal Energy Efficiency Ratio, SEER) conceived for building applications and not for industrial ones. The performance of chillers and air-conditioners being highly variable depending on the load, the capacity control strategy and the external temperature (either dry or wet bulb, for air- and water-cooled systems), such simplified approaches are very error-prone and the results cannot offer reliable figures for planning an investment. Useful arguments to estimate the error induced by such simplified approaches are proposed in this paper, which ultimately lead to the formulation of novel and customized seasonal efficiency indicators for chillers installed in wineries. The paper is structured as follows:

- A general description of the processes involved in winemaking is given, with a particular focus on the energy-intensive steps and on the qualitative characterization of cooling requirements.

- A novel procedure to estimate the cooling energy load profiles and assess the potential savings in electricity for cooling energy requests is proposed. In particular, the estimation of energysaving potential by use of conventional seasonal performance indicators is critically discussed, highlighting the risks of under- or over-estimation due to the use of incorrect weighting factors or boundary operating conditions.

- The proposed method is applied to a medium-scale winery located in Southern Italy, developing accurate annual load profiles and analyzing the operating conditions of chillers with the aim of defining a novel user-oriented seasonal efficiency indicator and quantifying the error that would result from using a conventional SEER.

- Some qualitative and quantitative conclusions are finally drawn.

\section{Fundamentals of energy use in the winemaking process}

In this section, a brief description of the winemaking process and its most energy-consuming steps is outlined. As clarified below, the sequence of steps depends on the type of wine being produced, and then the production phases are consecutively numbered only for the sake of clarity. In order to provide a more intuitive vision of the whole process, a schematic representation is given in Fig. 1.

Step 1. Harvesting the grapes

The fruit is harvested at a scheduled time at the vineyard, and then the grapes are transported to the winery by tracks. 


\section{Step 2. De-stemming and crushing}

After measuring the sugar content, the stems are removed from the grapes to limit the wine's bitterness. The product is then crushed to obtain a mixture of juice, skins, seeds and pulp which is called must. At this step electricity is mainly consumed, for moving the product and processing it; some cooling energy may be required, depending on the temperature of the grapes at delivery. After this step, the must is pumped into the fermenting tanks (for red wines) or to the pressing stage (for white wines).

\section{Step 3. Draining and pressing}

The must can be drained in vertical tanks, with the juice drained through filters located in the bottom. Alternatively, a press can be used to extract the juice. The membrane press is the most common pressing technology, and the speed and pressure of the press may influence juice content in terms of tannins and suspended solids, and will consequently influence the quality of the wine. Electricity is consumed to drive the motor, pumps and compressors.

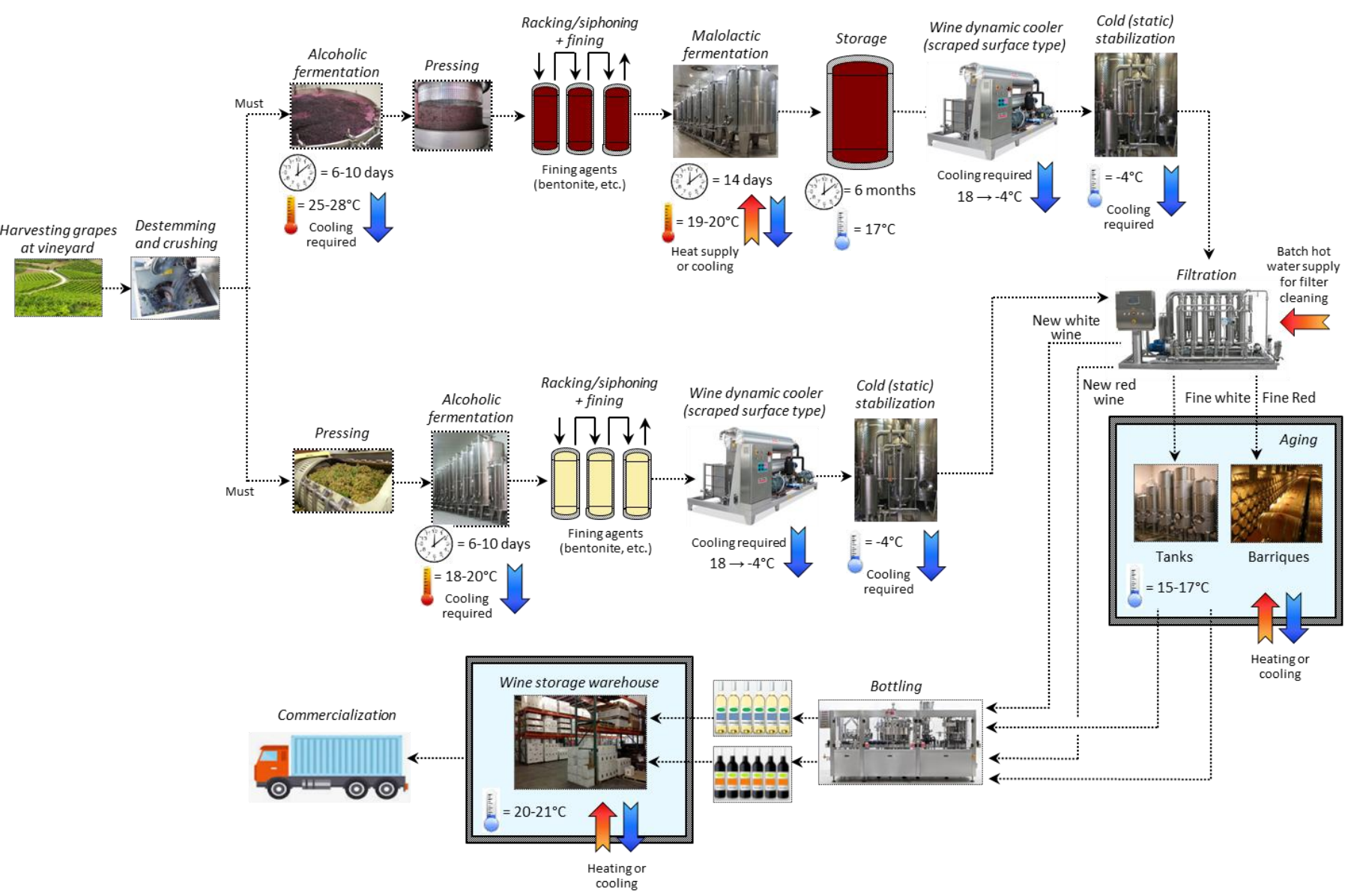

Figure 1. Schematic overview of the winemaking process in a winery

\section{Step 4. Alcoholic fermentation}

This is a crucial phase of the winemaking process, which must be controlled accurately to warrant the desired taste and quality of the wine. During fermentation, yeasts convert the sugars to alcohol and carbon dioxide, according to the following reaction:

$$
\mathrm{C}_{6} \mathrm{H}_{12} \mathrm{O}_{6} \rightarrow 2 \mathrm{CH}_{3} \mathrm{CH}_{2} \mathrm{OH}+2 \mathrm{CO}_{2}+137.9 \mathrm{~kJ}
$$


Fermentation usually takes place in stainless steel tanks (more rarely in oak barrels), and the temperature must be accurately controlled both at the beginning and during the whole process in order to guarantee the desired quality. The fermentation heat and the undesired heat gains through the tank envelope must be removed. The duration of the fermentation phase can vary highly, being in the order of 7-10 days for most wines although fermentation periods of up to 40 days may be required for highquality wines. The optimal temperature inside the tanks also depends on the product, ranging between 18 and $20^{\circ} \mathrm{C}$ for white wines and between 25 and $28^{\circ} \mathrm{C}$ for red ones. As mentioned above, for red wines the juice of the must is fermented with skins, seeds and pulp, whereas these solids must be removed before fermentation (i.e. during the pressing stage) when white wine is being produced. Cooling is guaranteed by circulation of chilled water or chilled water-glycol mixtures inside the jackets of the fermentation tanks. The tanks are not completely filled since a small volume at the top is used to host the relevant amount of foam produced during the so-called primary fermentation (i.e. the first days of the process, when the yeasts convert up to $70 \%$ of the sugar quite rapidly). In this regard, the thermal effects of pump-overs performed to improve the extraction of flavanols, tannins and anthocyanins must be accounted for. An interesting study by Guerrini et al. [37] identified two main effects of pump-overs on grape juice temperature, namely the reduction of the temperature gradient within the juice (homogenizing effect) and the increased efficiency of heat exchange resulting in faster juice cooling.

\section{Step 5. Malolactic fermentation}

This phase does not involve an actual fermentation process, but rather a spontaneous conversion of malic acid into lactic acid which naturally occurs under the appropriate conditions (temperature between 18 and $20^{\circ} \mathrm{C}, \mathrm{pH}$ of the wine in the 3.4-4.0 range, low content of sulfur dioxide), based on the reaction:

$$
\mathrm{COOH}-\mathrm{CH}_{2}-\mathrm{CHOH}-\mathrm{COOH} \rightarrow \mathrm{CH}_{3}-\mathrm{CHOH}-\mathrm{COOH}+\mathrm{CO}_{2}
$$

Most red wines undergo malolactic fermentation, which is deemed important for softening the wine taste, making its flavour rounder and fuller. New white wines do not undergo malolactic fermentation, which is used only for some dry white wines before aging in barriques. Due to the absence of fermentation heat and the moderate temperature, the cooling energy requests for this process are usually low.

\section{Step 6. Clarification and stabilization}

The clarification separates the clear wine from the spent yeasts and other solids remaining after fermentation. It is usually achieved by racking, i.e. siphoning off the clear wine from one barrel to another using gravity after the lees have settled to the bottom. Filtering and fining (i.e. stirring a fining agent heavier than water and alcohol into the wine) can also be used to separate suspended particles. Cold stabilization is then used to remove the excess tartaric acid, requiring the wine to be chilled to temperatures between -4 and $0{ }^{\circ} \mathrm{C}$. Dynamic cooling of the wine from its $16-18^{\circ} \mathrm{C}$ temperature in the storage tanks down to $-4^{\circ} \mathrm{C}$ and maintaining the wine at this low temperature for the whole stabilization period are two of the most energy-consuming phases of the winemaking process.

\section{Step 7. Storage and/or aging}

After clarification, the wine is stored and maintained at an appropriate temperature. Accurate control is required to ensure that chemical reactions in the wine do not affect its quality. To this end, the barrel 
cellars usually have strict temperature and humidity controls, based on the mechanical ventilation of external fresh air and/or artificial cooling. The temperature to be maintained, as well as the duration of the aging period, are strongly dependent on the type of wine.

\section{Step 8. Bottling and corking}

Bottling is the last step in the process occurring in wineries, and it usually takes place in a bottling facility in-house, maintained under slightly positive air pressure to limit the risk of wine contamination. Bottles are cleaned by blowing compressed air into each bottle (with non-negligible electricity consumption) and are then filled with wine and corked.

\section{Step 9. Storage and commercialization}

The bottles are usually stored in a warehouse where the temperature is controlled, usually being maintained in the $19-21^{\circ} \mathrm{C}$ range. Then trucks are used to distribute the product to the commercial chain.

\section{A novel procedure to develop cooling load profiles and assess energy-saving potential from efficient cooling energy production}

In this section, a procedure aimed at quantifying the potential energy savings achievable through retrofit of chilling units in wineries is proposed. The procedure is designed for those wineries where the plant managers and operators do not have detailed knowledge about their cooling energy uses. As reported by surveys available in the literature $[9,12]$ and based on the authors' experience, this is a very common condition in wineries, since in most cases the operators fail to perform accurate and expensive energy audits and the electricity load profiles provided by energy consultants are aggregated on a "total site" basis and hence do not indicate "where" and "when" cooling energy is consumed.

The procedure essentially consists of two main steps, which will be presented separately below:

1. Simplified and approximate bottom-up approach to develop cooling load profiles in a winery, based on historical wine production and energy consumption data and on the available datasheets of components;

2. Assessment of potential electricity savings achievable by replacing the installed chillers and/or air conditioning units (if obsolete) with modern and more efficient ones. A rough approach frequently adopted in the wine industry will be introduced and critically discussed, pointing out its main weaknesses. Then a more reliable method will be presented, which takes into account the expected operating conditions of the chillers throughout the year.

\subsection{Development of cooling load profiles}

In order to develop reliable profiles of cooling loads required to abate and/or maintain the temperature of must, juice and wine within the required limits and to control the temperature and humidity of cellars and warehouses, a measurement campaign should be carried out for at least one whole year. Also, in principle, a complex methodology to develop process step models and to identify all energy flows should be implemented, according to the approach presented by Hyman et al. [38]. In this section, a simplified approach is proposed, based on the collection of a limited amount of data easily available to a winery's management and regarding: (i) the daily production levels (records of wine bottles produced, classified by type of wine), (ii) the installed equipment and their technical specs included in datasheets, and (iii) the historical electricity consumption, simply derived from bills. A schematic view of the procedure is given in Fig. 2. 
Although the different steps of the procedure are consecutively numbered in Fig. 2, some of them are not strictly sequential and they could be carried out in reverse order. The method essentially compares:

a. the annual electric consumption for refrigeration and space cooling calculated by a bottom-up approach, i.e. moving from a simplified calculation of each individual load (Steps 1 to 5 in Fig. 2);

b. the annual electric consumption for refrigeration and space cooling obtained by considering the "total site" electricity consumption derived from bills and subtracting the electricity consumption for uses other than refrigeration and space cooling (Step 6 in Fig. 2).

Since the refrigeration loads for the process are essentially related to bringing the must, juice or wine to the desired temperature and maintaining it at the setpoint conditions inside the tanks for long periods, the bottom-up calculation of these loads requires:

- The preliminary calculation, at each time period, of the amount of must or wine undergoing any specific phase of the process (Step 1 in Fig. 2). Since daily records of bottled wine (classified per type) are available, as well as records of the daily input of grapes during the harvest period, and knowning the duration of each phase of the wine-making process, the amount of must and wine undergoing, at any date, each specific phase of the winemaking process can be estimated. This task, which can be easily accomplished with the support of a process-engineer or enologist, provides as output the record of material flows in the winery, allowing, for instance, the calculation of how much red wine, in hectolitres (and then, how many tanks), was approximately undergoing cold stabilization at an exact date;

- Based on the amount of must/wine undergoing each phase of the process, the process-related cooling loads can be calculated as follows (Step 2 in Fig. 2):

- With regard to fermentation tanks, the cooling energy required in a $\Delta \tau$ period to control the temperature is calculated as the sum of heat gains through the tank envelope (to be calculated based on internal and external temperatures) and the heat of fermentation to be removed:

$$
C_{\text {ferm }}=\int_{\Delta \tau}\left[k_{\text {loss }} U A\left(T_{\text {air }}-T_{\text {ferm }}\right)+\dot{m}_{\text {ferm }} \cdot S C_{\text {must }} \cdot 137.9\right] d \tau
$$

where $\mathrm{C}_{\text {ferm }}$ is the cooling energy required to control the temperature in the fermentation tanks, $\mathrm{U}$ indicates the global heat transfer coefficient of jacketed steel insulated tanks (typical value is $\mathrm{U}=0.65 \mathrm{~W} /\left(\mathrm{m}^{2 \circ} \mathrm{C}\right)$ ), $\mathrm{T}_{\text {air }}$ and $\mathrm{T}_{\text {ferm }}$ are the temperatures of external air and fermenting must, $\mathrm{k}_{\text {loss }}$ is a correction factor accounting for possible thermal bridges in tank geometry, $\dot{m}_{\text {ferm }}$ and $\mathrm{SC}_{\text {must }}$, respectively, indicate the mass of fermenting wine per unit time and its sugar content (in mol per kg of must), with $137.9 \mathrm{~kJ} / \mathrm{mol}$ being the fermentation heat;

- For the phase of wine storage/aging in tanks, the cooling energy can be calculated using the same equation, considering only the term related to heat gains through the tank envelope and assuming the storage temperature of the product, $\mathrm{T}_{\text {prod; }}$;

- With regard to rapid (or dynamic) cooling of wine before entering the cold stabilization tanks, the amount of heat to be subtracted may be calculated by:

$$
C_{\text {rapid cooling }}=\int_{\Delta \tau} \dot{m} c_{p}\left(T_{\text {in }}-T_{\text {fin }}\right) d \tau
$$

where $\mathrm{T}_{\text {in }}$ and $\mathrm{T}_{\text {fin }}$ indicate the initial and target temperatures of the product (typically in the order of $17^{\circ} \mathrm{C}$ and $-4^{\circ} \mathrm{C}$, respectively) and $\mathrm{c}_{\mathrm{p}}$ is the specific heat of juice and wine which can be assumed to be equal to $3.4 \mathrm{~kJ} / \mathrm{kg}^{\circ} \mathrm{C}$; 
(1) calculation of amounts of must or wine processed at each time step - Use record data for wine bottled in each time step (per type of wine)

- For each type of wine, based on its specific features (duration of each subprocess), a historica schedule of the phases of th process that the wine is undergoing at each time step is built up.

\section{(3) Calculation of space cooling loads}

- Identification of air-conditioned volumes (cellars, warehouses, offices) and factors affecting energy loads (envelope features, air infiltration, etc.)

- Identification of temperature and humidity setpoints for each volume

- Use of a simulator with libraries of local weather data to calculate space cooling loads $\mathrm{C}_{\text {air-con }}$

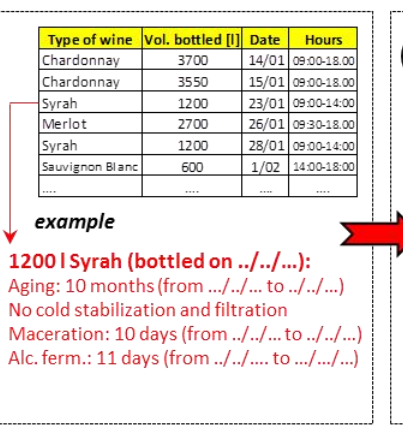

(2) Calculation of cooling loads from jacketed water-cooled tanks - Estimation of amounts at each time step in temperature-controlled tanks

- Calculation of heat step) of water-cooled tanks, through the
general equation: $\quad C_{\text {prod }}=\int_{\Delta \tau} \dot{C}_{\text {prod }}=\int_{\Delta \tau} k_{\text {loss }} U A\left(T_{\text {air }}-T_{\text {prod }}\right)$

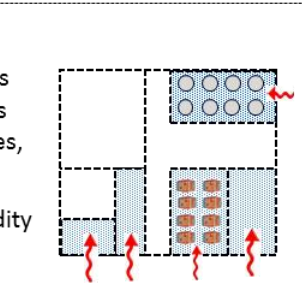

(4) Calculation of undesired heat gains in cooling energy storage and distribution - Identification of distribution pipes, assessment of thermal insulation condition and estimation of heat gains in cold water circuits, $C_{\text {pipe }}$

- Estimation of heat gains in cold water storages serving as capacity in the hydronic circuit

$C_{\text {stor }}=\int \dot{C}_{\text {stor }}=\int k_{\text {loss }} U A\left(T_{\text {ext }}-T_{\text {stor }}\right)$

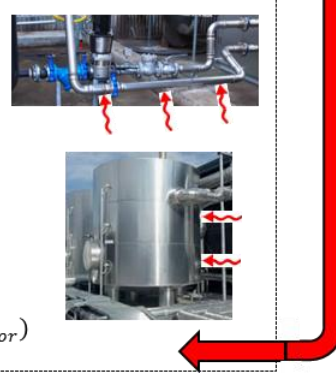

(5) Estimation of annual electric consumption for refrigeration and space cooling

- Evaluation of expected average Energy Efficiency Ratio of water chillers under their actual (not rating!) operating conditions

- Calculation of electricity consuption to drive the chillers and their auxiliaries, based on the Eq.

$$
E_{\text {ch+aux }}^{\text {calc }}=\frac{\int_{\text {year }}\left[\dot{C}_{\text {air-cond }}(t)+\dot{C}_{\text {prod }}(t)+\dot{C}_{\text {pipe }}(t)+\dot{C}_{\text {stor }}(t)\right] d t}{E E R_{\text {real }}^{\text {avg }}}
$$
of must or wine stored gains (in each time

Estimation of annual electric consumption for refrigeration and space cooling based on data from bills

(6) Estimation of annual electric consumption for refrigeration and space cooling from bills

- Collect data on all the appliances consuming electricity for scopes different from cooling (i.e. air compressors, lighting, pumps and motors)
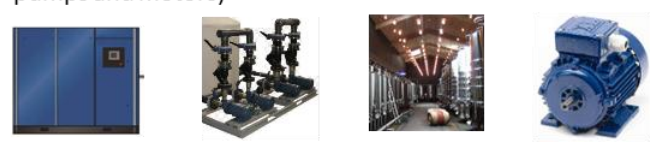

- Estimate their equivalent number of utilization $h$ on an annual basis, thus calculating their annual consumption:

$E_{\text {other uses }}=\sum h_{\text {pump }} \dot{E}_{\text {pump }}^{\text {nom }}+\sum h_{\text {lamp }} \dot{E}_{\text {lamp }}^{\text {nom }}+\sum h_{\text {comp }} \dot{E}_{\text {comp }}^{\text {nom }}+\sum h_{\text {mot }} \dot{E}_{\text {mot }}^{\text {nom }}$

- Calculate the total electricity consumption of the winery from bills

- Calculate the annual electricity consumption for refrigeration and space cooling:

$$
E_{\text {chtaux }}^{\text {bills }}=E_{\text {total }}^{\text {bills }}-E_{\text {other } u s e s}
$$

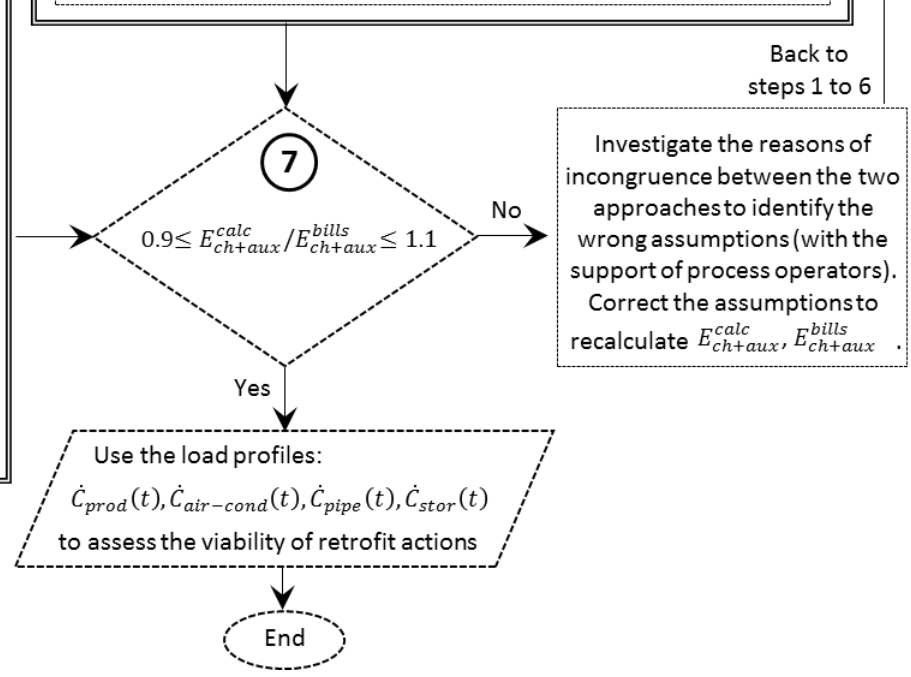

Figure 2: Schematic view of the proposed procedure to develop cooling load profiles of the winery 
- The calculation of space cooling loads (Step 3 in Fig. 2) requires a preliminary identification of the air-conditioned volumes, the setpoint temperatures, the features of envelopes and the assumption of consistent infiltration or air-exchange rates. In particular for warehouse cellars, high infiltration rates related to the open doors needed for product movement by forklifts should be considered, while mechanical ventilation is usually implemented in barrique areas to guarantee removal of transpired effluents and to facilitate strict control of humidity.

- In order to provide a more reliable estimation of cooling loads, the undesired heat gains along the cold water distribution pipes and through the cooling energy storage tank (which is always adopted to guarantee stable operation of chillers) must be accounted for (Step 4 in Fig. 2).

- Finally, the total electrical consumption to cover the total refrigeration and space cooling loads can be estimated by using an average Energy Efficiency Ratio, EER real (Step 5 in Fig. 2). In this regard, the subscript "real" indicates the need to calculate an average EER of the chiller(s) based on its (their) actual operating conditions throughout the year, and then taking into account the annual profile of requests, the capacity control strategy and the boundary conditions which strongly influence the performance. This concept will be discussed in more detail in the next subsection when the procedure for assessing the energy-saving potential will be analyzed.

The alternative top-down strategy to calculate the electrical consumption for refrigeration and space cooling (Step 6 in Fig. 2) based on the use of total site electricity consumption derived from bills, requires an estimation of the electricity consumption for uses other than refrigeration and space cooling. Usually the rated power consumption of air compressors, pumps, lighting devices and other electric motors are known, and estimating the consumption for these electrical uses essentially requires the assumption of reasonable utilization factors. The electricity consumption for refrigeration and airconditioning is calculated as the difference between the total site consumption and the energy consumed for uses other than refrigeration.

Finally, the electrical consumption for refrigeration and space cooling obtained by the two approaches described above are compared and, in the case that a relevant discrepancy is observed, the assumptions made in Steps 1-5 and in Step 6 (this last being particularly critical so that 24-hour monitoring of pump activation can be considered) are gradually adjusted based on an accurate check with the personnel.

\subsection{Assessment of potential energy savings and viability of retrofit strategies for the cooling system}

Due to the high incidence of energy costs for refrigeration and air-conditioning in a winery, it is often convenient to assess the viability of replacing the existing chillers and air-conditioners, when obsolete or characterized by poor energy performance, with modern units guaranteeing lower energy consumption. The analysis proposed below discusses the reliability of procedures aimed at calculating achievable energy savings.

In real-world applications, a very simplified approach is often adopted to estimate the potential electricity saving, $\mathrm{E}_{\text {saving, }}$, based on:

1. an estimation of the total cooling energy, $\mathrm{C}_{\text {year }}$, requested in a whole year that must be produced by the chiller under consideration for possible replacement; 
2. the use of a single performance indicator, usually the Energy Efficiency Ratio, to calculate the amount of electricity that the existing chiller (or air-conditioner) and the new model considered for possible replacement would consume, on a yearly basis, to produce this cooling energy:

$$
E_{\text {saving }}=\frac{C_{\text {year }}}{E E R^{\text {exist. }}}-\frac{C_{\text {year }}}{E E R^{\text {new model }}}
$$

The second step in the procedure is eventually implemented with different levels of accuracy, resulting in more or less reliable results:

a. The EER values used in the above equation are the values reported in spec sheets of the existing chiller and the new model to be installed. This approach leads to an extremely poor prediction of potential savings because the use of these EERs is not appropriate for at least two reasons: (i) the EERs are certified by manufacturers under rating conditions (inlet and outlet temperatures of chilled water and cooling medium) that dramatically differ from the common operating conditions of chillers in wineries, where the "water+glycol" mixture is often cooled down to below $0^{\circ} \mathrm{C}$; (ii) the EER ratings are calculated at a fixed operating point, while the refrigeration machine actually varies its operating point continuously throughout the year, varying its instantaneous EER as a consequence;

b. The EER values used in Eq. 5 are the EER ratings declared by manufacturers, adjusted to account for the off-rating operating condition of the chiller based on a simple performance map (available in tabular form) where the EER is given as a function of evaporation and condensation temperatures. This approach overcomes limit (i) indicated in the point a above, but not limit (ii), leading to quite a poor prediction of the potential savings;

c. A seasonal energy efficiency ratio is used instead of a simple EER calculated at a fixed operating point. This indicator attempts to reflect the average operational EER of the plant throughout the year, taking into consideration both the variable load conditions and external temperatures that influence its instantaneous performance in each period. It is formulated as:

$$
\begin{aligned}
\text { SEER }= & a \cdot E E R_{100 \%}\left(T_{100 \%}^{\text {chill. }}, T_{100 \%}^{\text {cool.med. }}\right)+b \cdot E E R_{75 \%}\left(T_{75 \%}^{\text {chill. }}, T_{75 \%}^{\text {cool.med. }}\right)+ \\
& +c \cdot E E R_{50 \%}\left(T_{50 \%}^{\text {chill. }}, T_{50 \%}^{\text {cool.med. }}\right)+d \cdot E E R_{25 \%}\left(T_{25 \%}^{\text {chill. }}, T_{25 \%}^{\text {cool.med. }}\right)
\end{aligned}
$$

In Eq. 6, the constants a, b, c and d indicate the fractions of the total cooling production with the chiller operating at $100 \%, 75 \%, 50 \%$ and $25 \%$ of its nominal capacity and serve as weighting factors for the EERs of the chiller at these four load conditions. These EERs are explicitly indicated to be a function of the temperature of the chilled fluid, $\mathrm{T}^{\text {chill. }}$, and the cooling medium (air or water in air-cooled and water-cooled chillers, respectively), $\mathrm{T}^{\text {cool.med. }}$ which may assume in turn different values in the four load conditions. The dependence of $\mathrm{T}^{\text {chill. }}$ from the load condition is usually neglected and this approach is consistent with the situation in wineries, where regardless of the amount of product being processed and the consequent load, the supply temperature of supplied chilled water is approximately constant. Then the SEER of a refrigeration unit is formulated as a simple function of the weighting factors $a-d$ and the EERs achieved in the four reference load conditions (calculated at four appropriate values of $\mathrm{T}^{\text {cool.med }}$ ). In principle, this approach should overcome both limits (i) and (ii) enumerated above and lead to a reliable estimation of electricity savings. 
However, in order to guarantee the correct application of SEERs and to achieve a reliable estimation of weighting factors a-d should be suited to the customer's cooling load profiles, while the appropriate

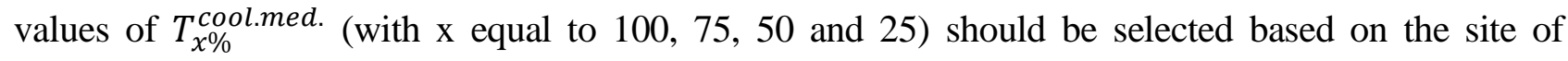
installation and the local temperatures of the available cooling medium.

Such a procedure is rarely implemented and standard SEERs are usually adopted, defined by certification companies for all the products to be distributed in a macro-region. The most common standard SEERs are the Integral Part Load Value (IPLV), mostly adopted in the Northern American market, and the European Seasonal Energy Efficiency Ratio (ESEER), used in Europe. In order to illustrate the conceptual weakness of using such indicators for chillers or air conditioners in industrial applications, the ESEER is discussed briefly here. This indicator adopts the weighting factors and reference temperatures of a cooling medium shown in Tab. 1 (values refer to air-cooled units).

Table 1: Reference temperature and weighting factors adopted in the ESEER indicator

\begin{tabular}{ccc}
\hline Part Load Ratio & $T^{\text {cool.med. }}$, i.e. air temperature $\left[{ }^{\circ} \mathrm{C}\right]$ & Weighting factor \\
\hline $100 \%$ & 35 & $\mathrm{a}=0.03$ \\
$75 \%$ & 30 & $\mathrm{~b}=0.33$ \\
$50 \%$ & 25 & $\mathrm{c}=0.41$ \\
$25 \%$ & 20 & $\mathrm{~d}=0.23$ \\
\hline
\end{tabular}

These values have evidently been conceived for building applications where the cooling load is mainly influenced by the external temperature and the related heat gains through the envelope (in fact, high load conditions correspond to high air temperatures). In industrial applications, the cooling loads are also influenced by the external temperature, but they are mainly related to the productive cycles, varying on a monthly, weekly and daily basis accordingly. A similar issue is encountered in cooling systems supplying data centers, where the load is barely influenced by external temperatures due to the prevalence of internal heat loads [39]. This is particularly evident in wineries, where the seasonal fluctuation of cooling loads is highly influenced by the periods of must fermentation and cold stabilization and by the duration of the wine storage/aging phases. With this in mind, a novel approach is proposed in this paper, based on the use of customer-oriented seasonal energy efficiency ratios (instead of standard SEERs), where:

- the correct values of the weighting factors a-d are drawn from the results of the detailed cooling load profiles;

- the correct reference temperatures of the cooling medium are obtained as a weighted average of the local temperatures in the time periods where the chillers operate at a given part load ratio.

A comparison between such customized weighting factors and reference temperatures and the corresponding values adopted in a standard seasonal indicator such as the ESEER could provide useful insights into answering the following question: how much is the error on the estimated electricity saving induced by the adoption of standard seasonal indicators when the existing chiller or air conditioner is assumed to be replaced with a new and more efficient one? 
The results of the whole procedure will be presented in the next sections for an illustrative case study.

\section{Analysis of a case study}

In this section, a case study is presented to highlight the potential of the proposed procedure. The section is structured into four subsections, respectively aimed at:

- introducing the case study with details about the winemaking process and the installed facilities;

- implementing the proposed procedure to audit the energy uses for refrigeration and space cooling;

- assessing the potential energy saving of retrofit interventions designed to produce the required chilled water more efficiently. In this subsection, a critical comparison between the reliability of different approaches will also be presented, pointing out that only the use of customized SEERs allows the analyst to assess the potential electricity saving reliably;

- discussing the results.

\subsection{Description of the examined winery}

The winery discussed here as a case study is located in Southern Italy and it has a production capacity of over 3 million litres of bottled wine per year. The winery stands over a $12400 \mathrm{~m}^{2}$ area. In Table 2, some basic information is given on the different areas and installed facilities.

Table 2. Basic information about the examined winery

\begin{tabular}{|c|c|c|c|}
\hline Use & $\begin{array}{l}\text { Total surface } \\
\text { area }\left(\mathrm{m}^{2}\right)\end{array}$ & Setpoint air conditions & Notes \\
\hline $\begin{array}{l}\text { Winemaking } \\
\text { process area }\end{array}$ & 2130.0 & $\begin{array}{l}\text { Space with no air } \\
\text { conditioning } \\
\text { (T and RH highly variable) }\end{array}$ & $\begin{array}{l}\text { The area is divided into } 5 \text { large } \\
\text { cellars, hosting insulated tanks for } \\
\text { fermentation, stabilization and } \\
\text { storage, and the filtration section }\end{array}$ \\
\hline $\begin{array}{l}\text { Bottled wine } \\
\text { warehouse cellars }\end{array}$ & 2100.0 & $\begin{array}{l}\mathrm{T}=21.5^{\circ} \mathrm{C} \\
\mathrm{RH}=63 \%\end{array}$ & $\begin{array}{l}\text { The area is divided into two large } \\
\text { cellars, served by two air-handling } \\
\text { units with total } 18,000 \mathrm{~m}^{3} / \mathrm{h} \text { air flow }\end{array}$ \\
\hline Barrel cellar & 1450.0 & $\begin{array}{c}\mathrm{T}=15^{\circ} \mathrm{C} \\
\mathrm{RH}=80 \%\end{array}$ & $\begin{array}{l}\text { The area is located below ground } \\
\text { level, and it is served by an air- } \\
\text { handling unit }\end{array}$ \\
\hline Bottling area & 825.0 & $\begin{array}{l}\text { Space with no air } \\
\text { conditioning }\end{array}$ & - \\
\hline Office area & 441.0 & $\begin{array}{l}\text { Individual air } \\
\text { conditioning }\end{array}$ & $\begin{array}{l}\text { Split systems installed for space } \\
\text { heating and cooling }\end{array}$ \\
\hline
\end{tabular}

The winemaking plant is located approximately $90 \mathrm{~km}$ from the vineyard where the grapes are harvested. The first steps in the winemaking process (destemming and crushing) are carried out close to the vineyard, where the alcoholic fermentation of red wine also takes place. Then the fermented red wine and the must for production of white wines are transported to the winery by trucks. In order to 
focus on the retrofit actions discussed in this paper aimed at reducing energy consumption for

\begin{tabular}{|c|c|c|c|}
\hline & Chiller \#1 & Chiller \#2 & Refrigerator \#3 \\
\hline Producer & Sordato & Climaveneta & Blue Frost \\
\hline Technology & Air-cooled water chiller & $\begin{array}{l}\text { Air-cooled water chiller with } \\
\text { heat recovery }\end{array}$ & $\begin{array}{c}\text { Air-cooled direct } \\
\text { expansion cooler, scraped } \\
\text { surface type }\end{array}$ \\
\hline $\begin{array}{l}\text { Capacity in rating } \\
\text { conditions }{ }^{\#}[\mathrm{~kW}]\end{array}$ & 458 & 466 & 197.6 \\
\hline $\begin{array}{l}\text { EER in rating } \\
\text { conditions } s^{\#}\end{array}$ & 2.70 & 2.61 & 1.79 \\
\hline $\begin{array}{l}\text { ESEER in rating } \\
\text { conditions }{ }^{\#}\end{array}$ & 3.64 & 3.61 & - \\
\hline $\begin{array}{l}\text { Operating } \\
\text { conditions }\end{array}$ & $\begin{array}{l}\text { The unit is connected to } \\
\text { a } 6.5 \mathrm{~m}^{3} \text { storage at } 2^{\circ} \mathrm{C} \\
\text { set point temperature } \\
\text { ("positive temperature } \\
\text { circuit") }\end{array}$ & $\begin{array}{l}\text { The unit operates with partial } \\
\text { heat recovery and it is } \\
\text { connected to a } 6.5 \mathrm{~m}^{3} \text { storage at } \\
-7^{\circ} \mathrm{C} \text { set point temperature } \\
\text { ("negative temperature circuit") }\end{array}$ & $\begin{array}{l}\text { The unit serves as a wine } \\
\text { dynamic cooler, to cool } \\
\text { down the product rapidly } \\
\text { to }-4^{\circ} \mathrm{C} \text { for stabilization }\end{array}$ \\
\hline $\begin{array}{l}\text { Capacity in actual } \\
\text { operating } \\
\text { conditions }{ }^{*}[\mathrm{~kW}]\end{array}$ & 387 & 265 & 191 \\
\hline $\begin{array}{l}\text { EER in actual } \\
\text { operating } \\
\text { conditions }\end{array}$ & 2.24 & 1.81 & 1.75 \\
\hline $\begin{array}{l}\text { ESEER in actual } \\
\text { operating } \\
\text { conditions }\end{array}$ & 3.02 & 2.50 & - \\
\hline
\end{tabular}

Table 3. Technical data regarding the capacity and performance of the installed chillers and operation must be discussed. In Tab. 3, details on the installed equipment are provided.

\# Rating conditions are conventional for air-conditioning applications $\left(12-7^{\circ} \mathrm{C}\right.$ on the water circuit, $+35^{\circ} \mathrm{C}$ for ambient air) for the two chillers, while $-5^{\circ} \mathrm{C}$ brine outlet temperature and $32^{\circ} \mathrm{C}$ ambient air temperature are the rating conditions for the dynamic direct expansion cooler

*Values derived from operation map of the units

The cooling system and circuits are schematically shown in Fig. 3, together with connections to the supplied loads and processes. 


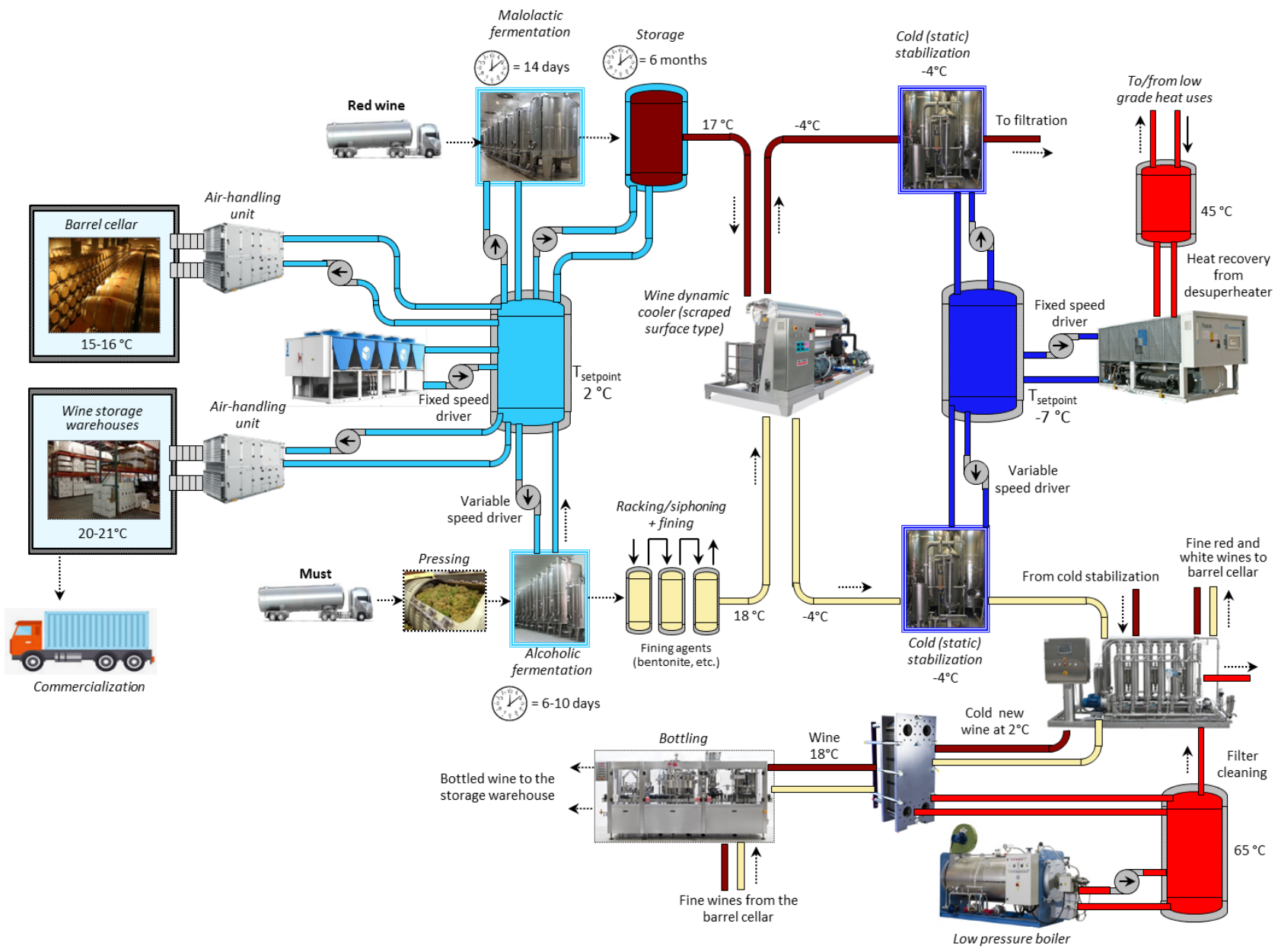

Figure 3. Schematic representation of the cooling system and circuits

\subsection{Implementation of the novel audit of cooling energy uses and results}

The proposed procedure for the development of reliable cooling load profiles (see Section 3.1) was implemented and the results are presented in this subsection, classified on the basis of the involved refrigeration unit and the supplied processes. Some details about the implementation of the procedure are given preliminarily, with particular reference to the bottom-up approach to the attainment of hourly load profiles (steps 1-4 in Fig. 2).

As shown in Fig. 4, the procedure is extremely easy to implement, not relying on the use of advanced tools but only on simple data sheets and solvers or commercially-available building energy load simulation software:

- Step 1: Source data regarding historical production of bottled wines, classified by type, are used as input for a dedicated data sheet, such as an Excel sheet;

- Step 2: Automated calculation of static cooling loads from fermentation, storage and stabilization tanks is made using a different Excel sheet. Overall heat transfer coefficients of tanks are drawn from catalogues, product temperatures are known by process control settings, and indoor temperature in the non-air-conditioned areas hosting the tanks are obtained by simulation in "free-floating" mode (details on the simulation tool are provided below); 
- Step 3: Space cooling loads and free-floating indoor temperatures in non-air-conditioned areas are calculated by a commercial simulation tool, Termolog EPIX 10 [40], which implements Building Information Modeling (BIM) technology and simplified load calculation algorithms accounting for all internal and external loads. The tool is conceived as a support instrument to certify Building Energy Performance or design energy-efficient envelopes and heatingcooling systems; it also includes a rich built-in library of wall structures, thermal bridges and Heating, Ventilating and Air-Conditioning (HVAC) systems;

- Step 4: Estimation of cooling energy losses through chilled water tanks and pipes requires some simple calculations and the use of correction factors, which are based on a preliminary visual and thermographic inspection to assess the conditions of thermal insulation.

The other steps of the procedure (steps 5-6 in Fig. 2) are not discussed in further detail, since they only require some simple calculations (the sum or difference between previously calculated loads) and interviews with plant managers and operators.
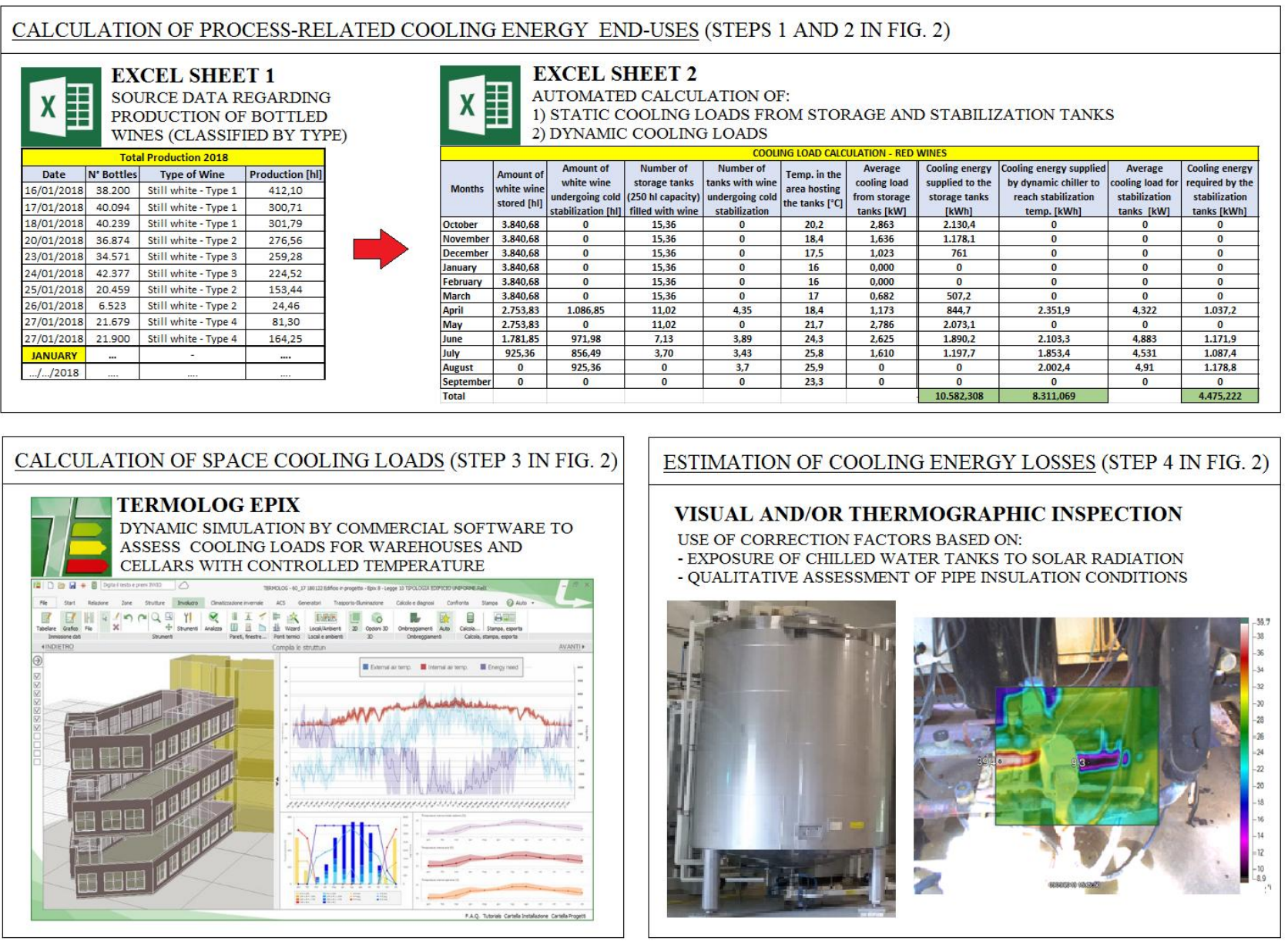

Figure 4: implementation stages of the bottom-up approach to calculation of hourly cooling loads

\section{2.a Cooling loads on the chiller supplying chilled water at positive temperature}

Chiller \#1, which produces chilled water-glycol at $2{ }^{\circ} \mathrm{C}$, essentially guarantees the temperature control of fermentation and storage/aging tanks and the chilled water for the air-handling units supplying the two large warehouses and the barrel cellar. The monthly load profiles, classified by 
individual loads, are presented in Fig. 5; in Fig. 6, conversely, the aggregate cooling loads on this "positive temperature" circuit are presented on an hourly basis.

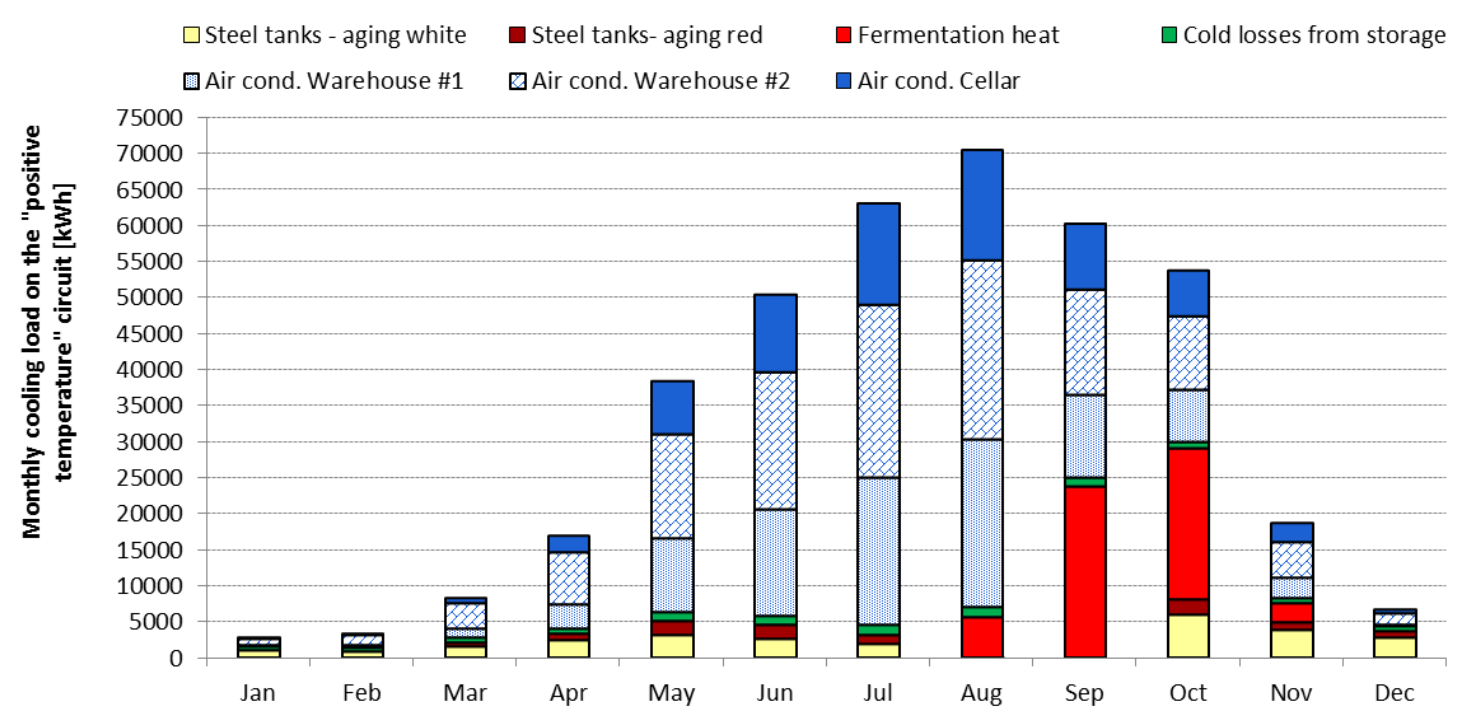

Figure 5: monthly cooling loads on the "positive temperature" circuit

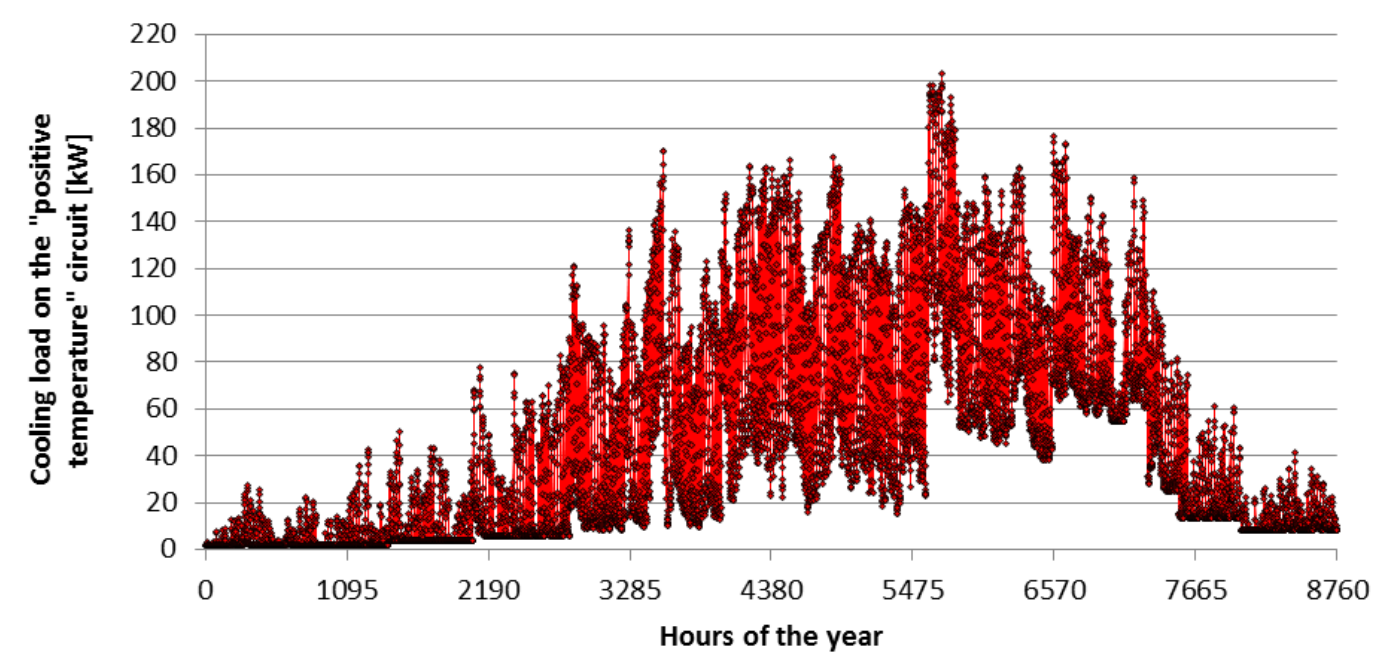

Figure 6: hourly cooling loads on the "positive temperature" circuit

It can be observed that the annual distribution of cooling loads is very similar to the distribution of the buildings. However, this result is peculiar to the examined winery, due to its large airconditioned areas (warehouses and cellars) and the consequent prevalence of cooling loads not related to the winemaking process. Since in other wineries warehouses are absent and wine is distributed immediately after being bottled, it is opportune to obtain load profiles for the processrelated cooling uses only, as shown in Fig. 7. 


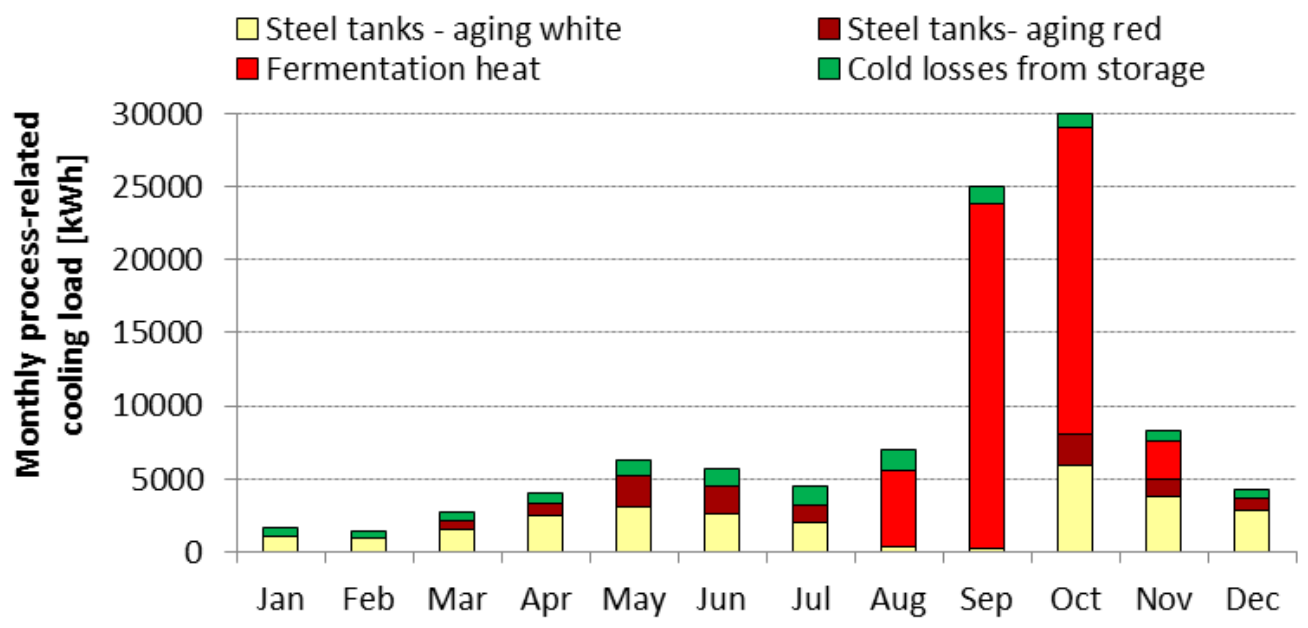

Figure 7: process-related cooling loads on the "positive temperature" circuit, on a monthly basis

It can be observed that the annual trend of process-related cooling loads on the "positive temperature" circuit is mainly influenced by the productive cycle, with a high share of the cooling energy being required during the fermentation period, particularly in September and October.

\section{2.b Cooling loads on the chiller supplying chilled water at negative temperature}

In this subsection, the cooling loads on the "negative temperature" circuit are presented in order to assess the operating conditions of Chiller \#2, which supplies a chilled water-glycol mixture at $-7^{\circ} \mathrm{C}$ for the cold stabilization of red and white wines. The monthly cooling load profile is shown in Fig. 8 .

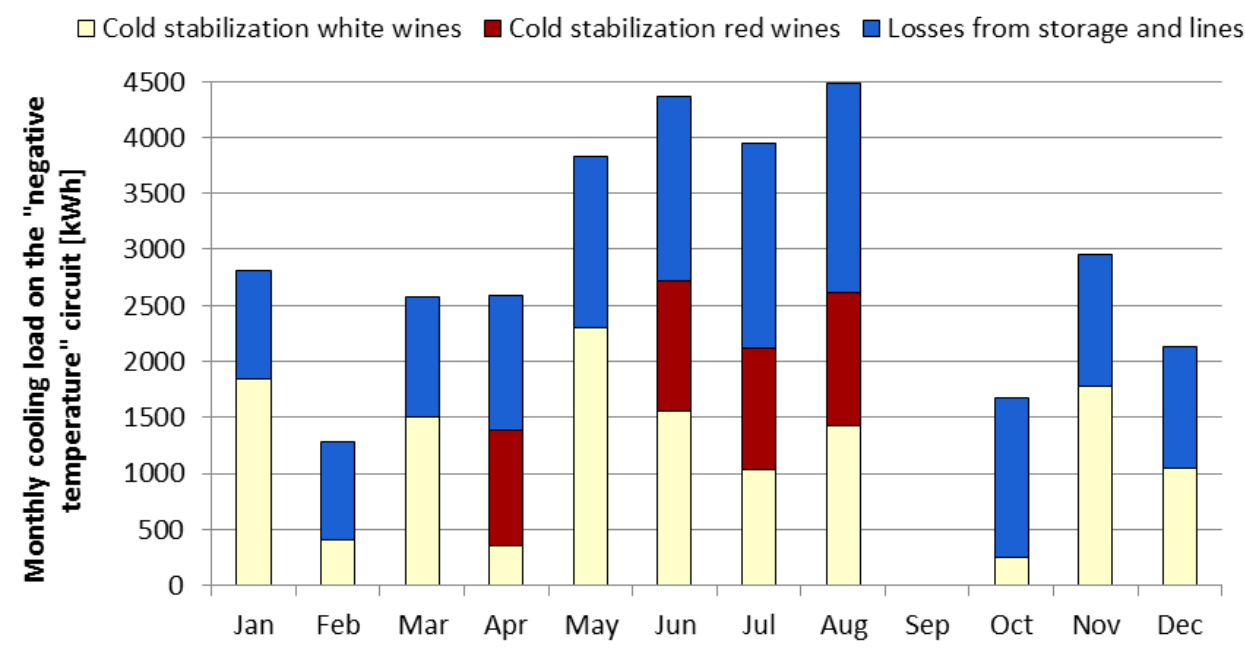

Figure 8: process-related cooling loads on the "negative temperature" circuit, on a monthly basis

It can be observed that cooling energy is required all through the year, except in September. Though the external temperature slightly influences the cooling loads, mainly due to the increase of cold 
losses through the storage envelope, the load profile is mostly influenced by the amount of wine undergoing cold stabilization at each period.

\section{2.c Cooling loads on the dynamic direct-expansion wine cooler}

As clarified in section 2, wine from the storage tanks must be rapidly cooled to $-4^{\circ} \mathrm{C}$ before entering the tanks where physical stabilization occurs. This process takes place in a direct-expansion scraped-surface type dynamic cooler. In Fig. 9, the cooling loads on this cooler are presented, on a monthly basis. It can be observed that these loads are negligibly influenced by external temperature, with very high requests being observed in the coldest month, i.e. January, and in months characterized by moderately low external temperatures, i.e. March, May and November.

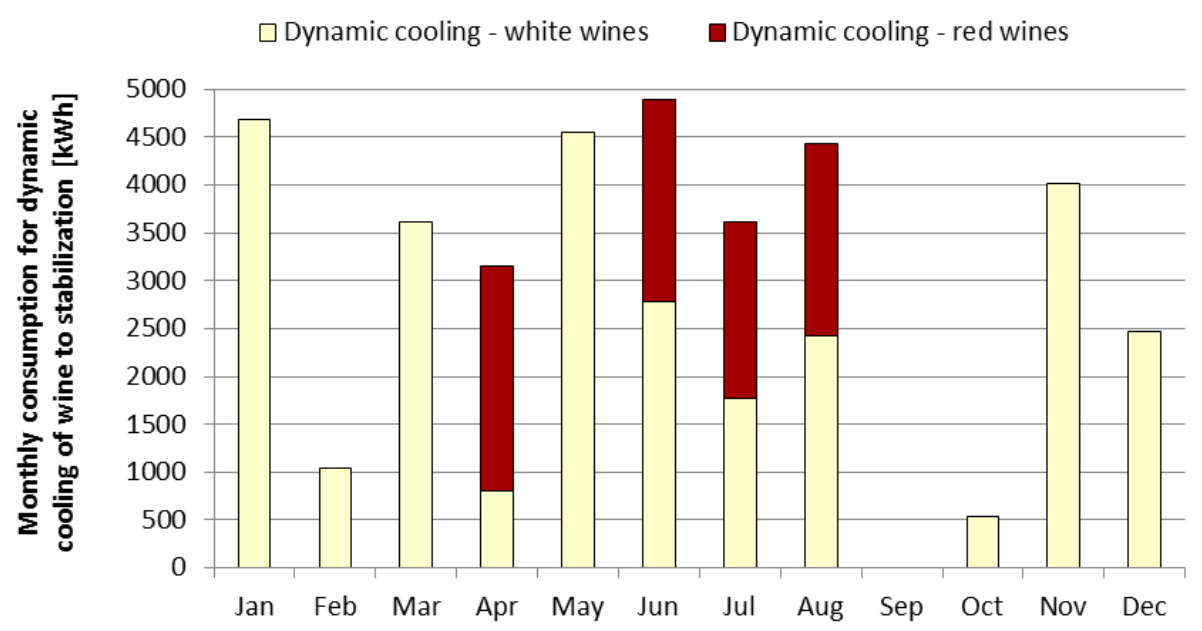

Figure 9: process-related cooling loads on the dynamic cooler, on a monthly basis

\subsection{Assessment of energy-saving potential by retrofit of the existing chillers}

A brief analysis of the technical specs presented in Table 3 suggests that the existing chillers are obsolete and exhibit much lower energy efficiency ratios than most modern chillers of the same capacity. The following retrofit actions are considered and assessed below in this section:

- Action 1, Replacement of Chiller \#1: the Sordato chiller currently supplying the "positive temperature" circuit is assumed to be replaced by a more modern and efficient unit of the same capacity, model Climaveneta NECS-N/CA 1716;

- Action 2, Replacement of Chiller \#2: the Climaveneta chiller currently supplying the "negative temperature" circuit is assumed to be replaced by a more modern and efficient unit of lower capacity (since the existing unit is also oversized), Airedale DeltaChill DCC022DR-06AKK0.

Performance data of these units are presented in Tab. 4. 
Table 4. Technical data of the chillers considered for replacement of the existing units

$\begin{array}{cc}\text { Replacement of } & \text { Replacement of } \\ \text { Chiller \#1 } & \text { Chiller \#2 }\end{array}$

Producer

Technology

Capacity in rating conditions ${ }^{\#}[\mathrm{~kW}]$

EER in rating conditions

ESEER in rating

conditions $^{\#}$

Operating conditions

Capacity in actual operating conditions ${ }^{*}[\mathrm{~kW}]$

EER in actual operating conditions ${ }^{*}$

ESEER in actual (i.e.) offrating operating conditions*
Climaveneta/NECS-N/CA 1716

Air-cooled water chiller, partial heat recovery, scroll compressors

453

The unit supplies the "positive temperature circuit" $\left(2{ }^{\circ} \mathrm{C}\right.$ set point temperature)
Airedale/DCC022DR-06AKK0

Air-cooled water chiller, no heat recovery, scroll compressors

220.1

The unit supplies the "negative temperature circuit" $\left(-7^{\circ} \mathrm{C}\right.$ set point temperature)

124.2

1.98

2.74

\# Rating conditions are conventional for air-conditioning applications $\left(12-7^{\circ} \mathrm{C}\right.$ on the water circuit, $+35^{\circ} \mathrm{C}$ for ambient air)

*Values derived from operation maps of the units

The electricity saving that can be achieved by replacing the existing units with new equipment is calculated here, based on the three simplified approaches presented in section 3.2 and on the use of Eq. 5, for the following scenarios:

- $1^{\text {st }}$ scenario: replacement of Chiller \#1 serving the "positive temperature circuit" with the new unit Climaveneta/NECS-N/CA 1716 for the supply of both space conditioning and process loads (i.e. the total loads presented in Fig. 5);

- $2^{\text {nd }}$ scenario: replacement of Chiller \#1 with the same new Climaveneta unit for the supply of chilled water for process loads only (presented in Fig. 7);

- $3^{\text {rd }}$ scenario: replacement of the existing Chiller \#2 serving the "negative temperature circuit" with the new unit Airedale DCC022DR-06AKK0 for the supply of cold stabilization loads (shown in Fig. 8).

From a rapid analysis of the results presented in Tab. 5 (see rows 3-5), it can be observed that the three simplified approaches discussed in section 3.2 lead to very different estimations of annual electricity usage. From a conceptual viewpoint, the reliability of the assessment should gradually 
increase when passing from the use of EER under rating conditions (approach "a" described in section 3.2) to the use of EER under the actual off-rating operating conditions (approach " $b$ " in section 3.2) and to the use of ESEER (approach "c" in section 3.2). With regard to the assessment of capacity, for EER and ESEER under actual off-rating operating conditions, it is worth mentioning that the supply temperatures of both units are outside the $5-11^{\circ} \mathrm{C}$ range for which performance data are available on the technical sheets. A linear regression of the manufacturers' data is used to extrapolate the units' performance under actual conditions; in order to guarantee the reliability of such a simplified approach, a simple model of the units developed by IMST-ART [41] is used and simulations are run at different supply temperatures, achieving a good agreement with the linear trends (deviations below $1 \%$ and $5 \%$ resulted for the chillers supplying the "positive" and "negative" temperature circuits, respectively).

However, as pointed out in section 3.2, this last approach is limited by the use of weighting factors

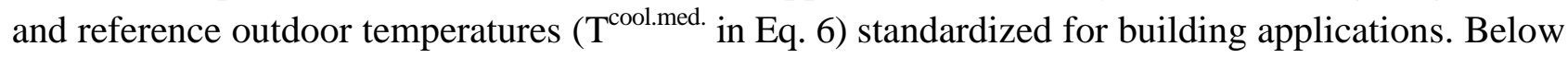
in this section, a critical analysis of the consequent errors is made, aimed at highlighting the need for customer-oriented seasonal energy efficiency ratios. Based on the results of the detailed energy audit presented in Section 4.2, detailed knowledge about the part load ratio of each chiller throughout the year and the external temperatures for each operating condition can be acquired.

Table 5. Examined retrofit scenarios and estimated energy savings

\begin{tabular}{|c|c|c|c|}
\hline & $1^{\text {st }}$ scenario & $2^{\text {nd }}$ scenario & $3^{\text {rd }}$ scenario \\
\hline $\begin{array}{l}\text { Annual cooling load supplied by the } \\
\text { new efficient unit [MWh] }\end{array}$ & 411.35 & 118.88 & 35.249 \\
\hline $\begin{array}{l}\text { Electricity saving estimated by the EER } \\
\text { in rating conditions (see section } 3.2, \\
\text { approach "a") [MWh] }\end{array}$ & 29.19 & 8.44 & 2.69 \\
\hline $\begin{array}{l}\text { Electricity saving estimated by the EER } \\
\text { in off-rating conditions (see section } 3.2 \text {, } \\
\text { approach "b") [MWh] }\end{array}$ & 45.14 & 13.04 & 1.67 \\
\hline $\begin{array}{l}\text { Electricity saving estimated by the } \\
\text { standard ESEER in off-rating } \\
\text { conditions (see section 3.2, approach } \\
\text { "c") [MWh] }\end{array}$ & 25.63 & 7.41 & 1.23 \\
\hline $\begin{array}{l}\text { Electricity saving estimated by the } \\
\text { customized SEER in off-rating } \\
\text { conditions defined according to the } \\
\text { procedure in section 4.3.a-c [MWh] }\end{array}$ & 24.80 & 4.03 & 0.784 \\
\hline $\begin{array}{l}\text { Percentage error (standard vs. } \\
\text { customized SEER) }\end{array}$ & $+3.35 \%$ & $+83.87 \%$ & $+56.89 \%$ \\
\hline
\end{tabular}

\# Rating conditions are conventional for air-conditioning applications 


\section{3.a Customized seasonal performance indicator for the $1^{\text {st }}$ scenario}

In order to discuss whether or not the assessed $25.63 \mathrm{MWh}$ electricity saving potential, derived in Tab. 5 by adopting a standard SEER (i.e. the ESEER), represents a reliable estimation for the $1^{\text {st }}$ retrofit scenario, a critical comparison between the annual distribution of cooling loads underlying the ESEER definition and the actual load distribution on the "positive temperature circuit" has to be made. In Fig. 10, a bubble chart of the cooling load distribution assumed by ESEER definition is shown, where on the vertical and horizontal axes the load condition and the reference temperature of the cooling medium are indicated, while the bubble area indicates the "weighting factors" a, b, c and $\mathrm{d}$ presented in Tab. 1. The slope of the dashed line connecting the bubbles indicates that the cooling load is assumed to increase with the external temperature, as is usual in buildings where the highest fraction of cooling loads is related with heat gains through the envelope [42]. In Fig. 11, a similar bubble chart is shown for the cooling loads on the "positive temperature circuit" considered in the examined $1^{\text {st }}$ scenario; the dashed line related to the ESEER definition is drawn here, again to allow for an easier comparison. It can be observed that the actual cooling load distribution shows a good agreement with the ESEER distribution, the highest load conditions mainly occurring in summer. This result can be further confirmed by the values of the weighting factors and temperatures of the cooling medium that would be obtained for a customized SEER designed on the actual loads under the examined $1^{\text {st }}$ scenario, according to the simple procedure described below.

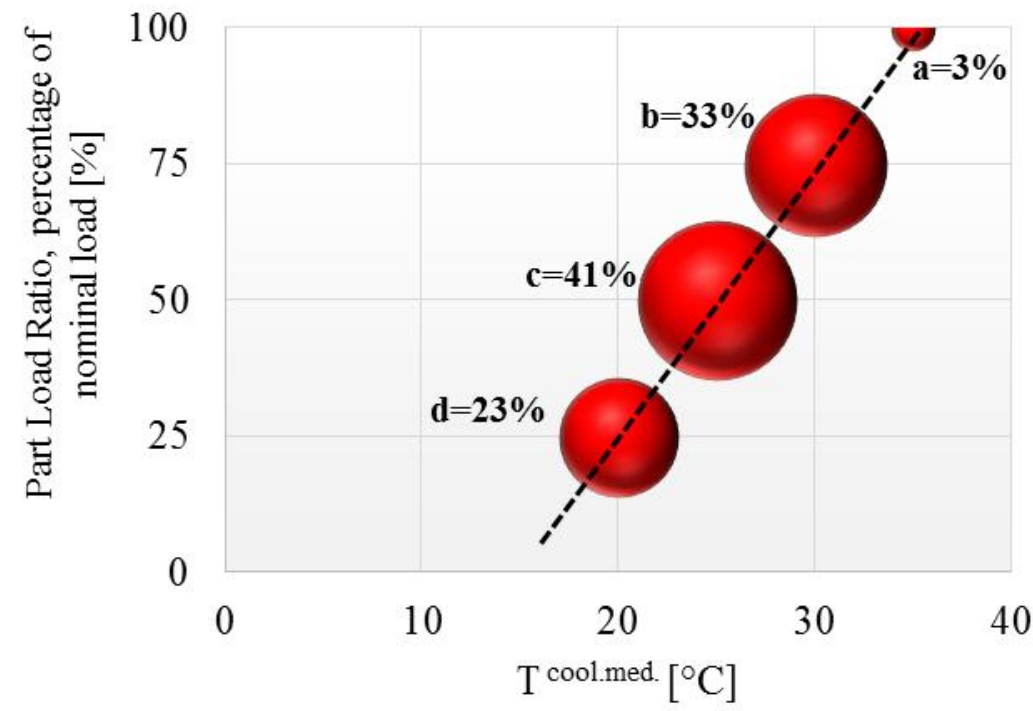

Figure 10. Annual distribution of cooling loads underlying the ESEER definition 


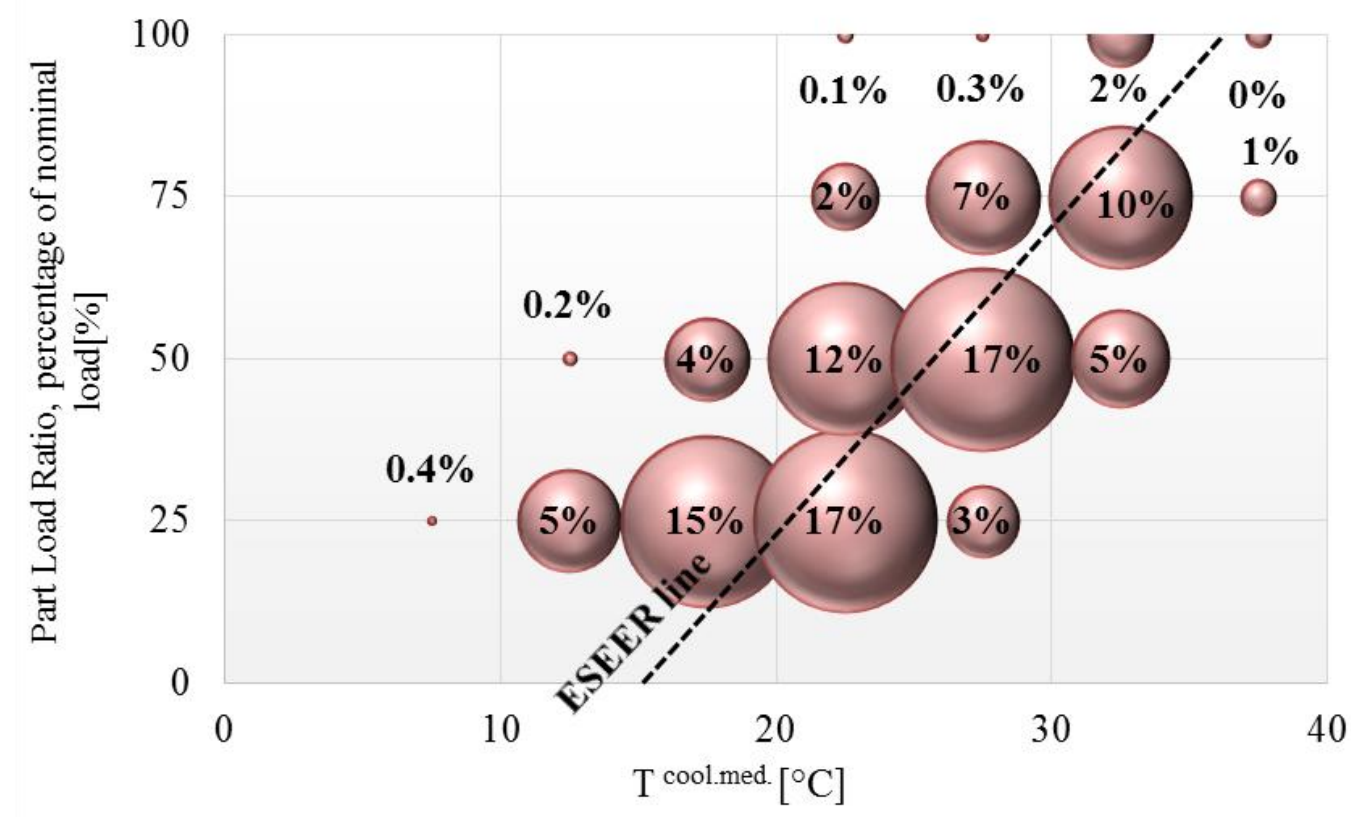

Figure 11. Annual distribution of the actual cooling loads on the "positive temperature circuit" to be supplied under $1^{\text {st }}$ retrofit scenario

A customized seasonal energy efficiency ratio can be defined based on the following approach:

- The weighting factors are calculated as ratios between the annual energy requests in a predetermined load range and the total annual load, according to Eqs. 7.a-d. Then, for instance, weighting factor $b$, which indicates the fraction of total energy supply with the chiller operating at a $75 \%$ capacity (see Eq. 6), is calculated from the actual load distribution accounting for all the cooling loads in the $62.5-87.5 \%$ range of the cooling load peak $\mathrm{C}^{\text {peak }}$.

$$
\begin{array}{cl}
a=\frac{\left(\sum C_{i}\right)_{{ }_{\text {s.t. }} C_{i} \geq 0.875 C^{\text {peak }}}}{\sum_{1}^{8760} C_{i}} ; & b=\frac{\left(\sum C_{i}\right)_{\text {s.t. } 0.625 C^{\text {peak }}} \leq C_{i} \leq 0.875 C^{\text {peak }}}{\sum_{1}^{8760} C_{i}} ; \\
c=\frac{\left(\sum C_{i}\right)_{\text {s.t. } 0.375 C^{\text {peak }} \leq C_{i} \leq 0.625 C^{\text {peak }}}}{\sum_{1}^{8760} C_{i}} ; & d=\frac{\left(\sum C_{i}\right)_{\text {s.t. } 0.125 C^{\text {peak }}} \leq C_{i} \leq 0.375 C^{\text {peak }}}{\sum_{1}^{8760} C_{i}}
\end{array}
$$

- The reference temperature of the cooling medium at a generic load condition " $\mathrm{x} \%$ " is calculated as a weighted average of the external air temperatures (the weights being the cooling loads) during the period where the load level is approximately $\mathrm{x} \%$ of the peak load:

$$
T_{x \%}^{\text {cool.med. }}=\left(\frac{\sum C_{i} T_{i}^{\text {cool.med. }}}{\sum C_{i}}\right)_{\text {s.t. } \operatorname{load}_{i}=x \%}
$$

The results are presented in Tab. 6, where a comparison between the values in the $2^{\text {nd }}$ column (referring to the ESEER) and the $3^{\text {rd }}$ column (referring to the customized SEER defined according to Eqs. 7 and 8) confirms that the cooling load distribution in the $1^{\text {st }}$ retrofit scenario is very similar to the standard underlying the ESEER. 
Table 6. Weighting factors and reference temperatures of cooling medium for the ESEER and the customized seasonal indicators for the three examined retrofit scenarios

\begin{tabular}{ccccc}
\hline & ESEER & $1^{\text {st }}$ scenario & $2^{\text {nd }}$ scenario & $3^{\text {rd }}$ scenario \\
\hline $\mathrm{a}$ & 0.03 & 0.029 & 0.347 & 0.375 \\
$\mathrm{~b}$ & 0.33 & 0.228 & 0.219 & 0.199 \\
$\mathrm{c}$ & 0.41 & 0.403 & 0.078 & 0.345 \\
$\mathrm{~d}$ & 0.23 & 0.34 & 0.333 & 0.081 \\
\hline$T_{100 \%}^{\text {cool.med. }}\left[{ }^{\circ} \mathrm{C}\right]$ & 35 & 35.33 & 19.80 & 26.04 \\
$T_{75 \%}^{\text {cool.med. }}\left[{ }^{\circ} \mathrm{C}\right]$ & 30 & 30.62 & 22.52 & 18.87 \\
$T_{50 \%}^{\text {cool.med. }}\left[{ }^{\circ} \mathrm{C}\right]$ & 25 & 25.42 & 24.85 & 14.24 \\
$T_{25 \%}^{\text {cool.med. }}\left[{ }^{\circ} \mathrm{C}\right]$ & 20 & 19.59 & 18.69 & 17.23 \\
\hline
\end{tabular}

As a consequence, the energy-saving potential estimated by using the ESEER is very close to the value obtained by using the customized SEER, as shown in Tab. 5 where it is evident that the use of the ESEER leads to a $3.3 \%$ overestimation of electricity savings. However, this result is peculiar, being motivated by the particular conditions of the examined winery where $71.1 \%$ of the annual cooling load on the "positive temperature circuit" is related to air-conditioning in the large warehouses and cellars. Since air-conditioning loads are mostly influenced by external temperatures, in this case, the use of a standard SEER conceived for building applications provides a reliable assessment of energy savings.

\section{3.b Customized seasonal performance indicator for the $2^{\text {nd }}$ scenario}

In order to increase the replicability of results for different wineries, it is worth discussing by a similar approach the potential energy savings that would be achieved when replacing Chiller \#1 to supply only the process-related cooling loads on the "positive temperature circuit", i.e. the loads related to fermentation, wine aging and losses presented in Fig. 7. In fact, in several wineries where bottled wine is immediately delivered to commercial areas (rather than being stored long-term in air-conditioned warehouses), the process-related cooling loads will represent the largest share of total loads. In Fig. 12, the bubble chart of process-related cooling loads on the "positive temperature circuit" is shown. It may be observed that these loads exhibit a much weaker correlation between the outdoor temperature (i.e. the temperature of the cooling medium, for air-cooled chillers) and the load levels, with less than $5 \%$ of annual loads occurring in the summer period when external temperatures are higher than $30^{\circ} \mathrm{C}$. Conversely, a relevant share of cooling loads occurs during mild climate periods, when the external temperature ranges between 15 and $25^{\circ} \mathrm{C}$. 
Also, unlike in building applications, most of the cooling loads are supplied either at very high load conditions (i.e. with the chiller operating at full load, in particular during the fermentation period) or very low load conditions (i.e. with the chiller supplying approximately $25 \%$ of its rated capacity, when cooling loads are only related with losses through aging tanks). Interpretation of these results can be intuitive when comparing Fig. 7 and Fig. 12.

Bubble distribution in Fig. 12 significantly diverges from the "ESEER line" (which reflects the part load vs. temperature correlation in buildings), and this deviation is even more evident in Tab. 6 where the customized weighting factors and reference temperatures of the cooling medium are presented. As a consequence, in this $2^{\text {nd }}$ retrofit scenario, an ESEER-based assessment of the energy-saving potential from chiller replacement is very error-prone, as evident in Tab. 5 where it led to calculating an energy saving of approximately twice the actual saving assessed by a customized definition of the seasonal performance indicator.

\section{3.c Customized seasonal performance indicator for the $3^{\text {rd }}$ scenario}

In this subsection, the same methodology is applied to assess the reliability of an ESEER-based evaluation of energy-saving potential from possible replacement of the chiller supplying the cold stabilization uses on the "negative temperature circuit".

In Fig. 13, the bubble chart of cooling loads on the "negative temperature circuit" is shown. Again, these loads exhibit quite a weak correlation between the outdoor temperature and the load levels, with less than $10 \%$ of annual loads occurring in the summer period, when temperatures higher than $30^{\circ} \mathrm{C}$ are experienced. Conversely, a relevant share of cooling loads for stabilization occurs during mild climate periods, when the external temperature ranges between 15 and $25^{\circ} \mathrm{C}$ and leads to operation of the unit either at full or at $50 \%$ load. This result is evident in the last column in Tab. 6 , where the reference ambient temperatures at the four examined load conditions are presented. 


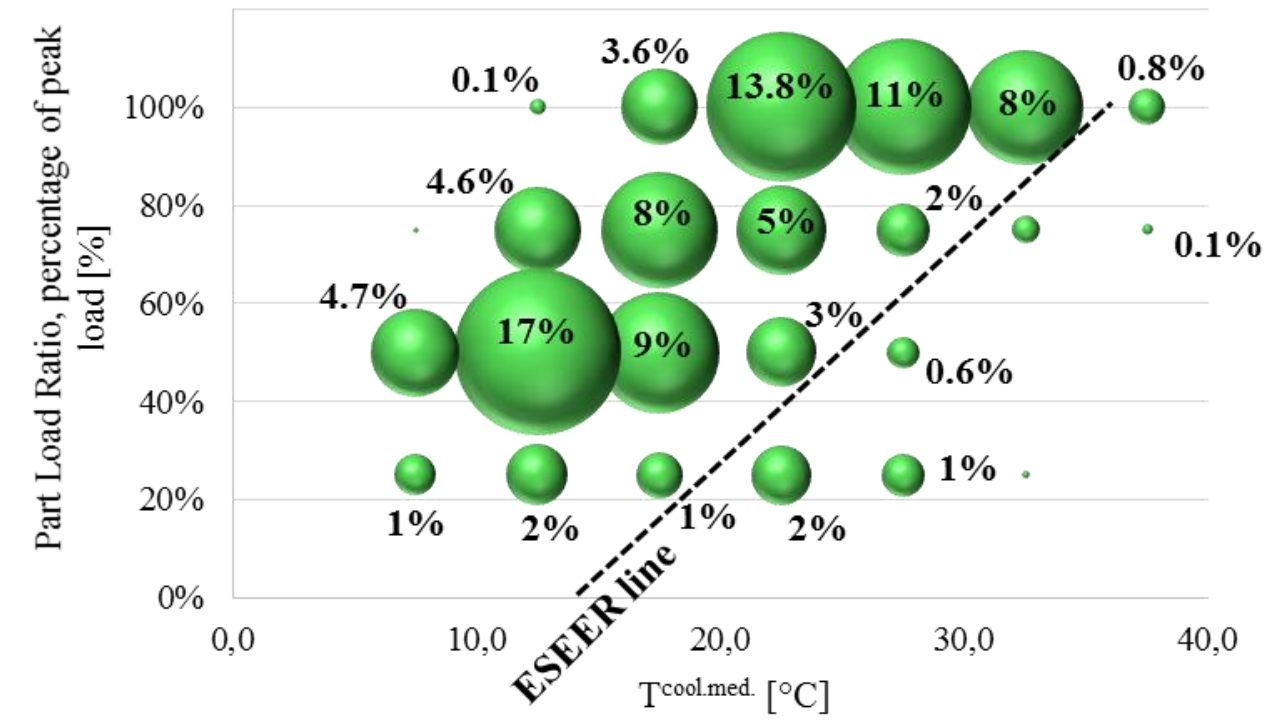

Figure 13. Annual distribution of the actual cooling loads on the "negative temperature circuit" to be supplied under $3^{\text {rd }}$ retrofit scenario

Once performed the calculation of the customized SEER, based on the weighting factors and reference temperatures derived for the chiller operating on the "negative temperature circuit", the potential energy saving deriving from replacement of "Chiller \#2" (see Tab. 3) with the more efficient model DeltaChill DCC022DR-06AKK0 was calculated. Results are presented in the last column in Tab. 5. It is evident that the use of standard SEERs (in this case, the ESEER) is revealed to be inadequate for assessing potential savings, leading to a $56.9 \%$ overestimation of these savings. The reason for such a poor assessment lies in the annual distribution of cooling loads on the "negative temperature circuit", which significantly differs from the cooling load distribution in buildings.

\section{3.d Discussion of results}

A brief analysis of the results obtained in subsections 4.3.a-c confirms that the assessment of energy-saving potential derived from replacement of obsolete chillers with more efficient ones is very error-prone when the rating values of energy efficiency ratios or standard seasonal efficiency ratios are adopted. This is because in the food and beverage industry, and in wineries in particular, the process cooling requests exhibit annual load profiles which differ significantly from those typical in buildings. This intuitive concept was substantiated by a quantitative analysis in a medium-scale winery, pointing out the need for customized seasonal efficiency indicators to be developed based on accurate preliminary audits of cooling loads.

It is worth discussing whether the presented results could be applicable to other wineries and to what extent the size and location of the winery could modify the results. With regard to the former aspect, it must be considered that wineries can significantly differ from one another, in terms of (i) types of wines produced (in particular, the share of sparkling to total wine production influences the energy requests), (ii) steps of the winemaking processes carried out in the factory ("from grape to 
wine" or only some of the production phases) and (iii) adoption of cold stabilization or other stabilization techniques, such as ion exchange. Depending on the distinctive features of the winery to be examined, the quantitative results could differ from those obtained and presented for the case study, but the proposed procedure would remain valid for developing reliable load profiles. Also, the size and location of the winery could significantly influence the results. Concerning the size, process-related cooling loads are less sensitive than other energy loads, being mainly influenced by the number of tanks, their spatial distribution and shape-factor (volume to external surface ratio) and some other variables related to the layout of the industrial plant. Regarding the climatic conditions, they usually imply moderate changes in the grape harvest time, while the external temperature can significantly influence the cooling loads related to losses through tank envelopes and distribution pipes. Again, the share between individual loads should be calculated for each individual winery since it can significantly differ from the one presented in section 4.2; conversely, the proposed bottom-up procedure and the critical arguments regarding the use of synthetic performance indicators can be in principle applied to any winery, regardless of its size and location.

As a final note, it can be observed that the relevance of some of the proposed arguments (such as the need for customized SEERs based on a novel definition of weighting factors and reference temperatures, see Eqs. 7-8) goes beyond this particular application, in principle being valid for industrial processes in different sectors. In the food and beverage industry, for instance, chillers operate with similar process-dependent annual profiles for the preservation of precooked foods, fruit juice concentrates, dried vegetables, etc., thus making the proposed approach suitable for energy-saving potential assessment in all these applications.

\section{Conclusions}

In this paper, a bottom-up methodology for the audit of air-conditioning and refrigeration loads in wineries was proposed, aimed at supporting analysts in developing accurate load profiles and identifying routes for possible improvements in energy efficiency. A critical analysis of the most common approaches for the assessment of potential electricity saving derived from replacement of obsolete or inefficient chillers and air-conditioners was proposed. In particular, the focus was given to the use of standard seasonal energy efficiency indicators, often perceived as a reliable means of assessing the total energy savings achievable on an annual basis. The proposed approach was applied to a medium-scale winery located in Southern Italy, deriving detailed load profiles for the process-cooling requests, properly disaggregated by temperature level. In terms of aggregate results, due to the presence of large air-conditioned warehouses and barrel cellars, air-conditioning resulted to be the largest cooling energy load, accounting for approximately $63 \%$ of total requests. Focusing the attention on process-related loads, $59.2 \%$ and $19.1 \%$ of cooling loads are respectively supplied at "positive" temperature $\left(2^{\circ} \mathrm{C}\right.$ chilled water for temperature control of fermentation and storage tanks) and "negative temperature" $\left(-7^{\circ} \mathrm{C}\right.$ chiller water-glycol for physical stabilization of wine), while dynamic coolers accounted for the remaining $21.7 \%$ of process loads. Looking more deeply at the annual cooling load profiles, the analysis revealed that process-related cooling loads exhibit a completely different distribution from the typical load profiles in buildings. In particular, 54.5\% of process cooling loads to be supplied by chilled water at positive temperature occur in September and October, i.e. in a mild climate period, being mainly related to temperature control of fermentation tanks. Cooling loads related to physical stabilization are more evenly distributed 
throughout the year, with $60.8 \%$ occurring in cold or mild climate periods. It was thus proven that any use of standard Seasonal Energy Efficiency Ratios, such as the European SEER, conceived for building applications is conceptually inappropriate for assessing the potential energy savings from chiller replacement. In the examined case, the ESEER-based assessment led to $83.9 \%$ and $56.9 \%$ over-estimation of savings, for the replacement of chillers supplying the "positive" and the "negative" temperature circuits, respectively. The proposed study attempts to issue a warning to energy analysts involved in research on efficient chilling and air-conditioning units, with respect to the need to account for their actual operating conditions in order to achieve a reliable prediction of their on-field performance.

\section{References}

[1] Joint Research Centre - European Commission. Energy use in the EU food sector: State of play and opportunities for improvement. Publications Office of the European Union, 2015, Luxembourg.

[2] Pantaleo A.M., Fordham J., Oyewunmi O.A., De Palma P., Markides C.N. Integrating cogeneration and intermittent waste-heat recovery in food processing: Microturbines vs. ORC systems in the coffee roasting industry. Applied Energy, 2018, Vol. 225, p. 782-796.

[3] Wu W., Beretta C., Cronje P., Hellweg S., Defraye T. Environmental trade-offs in fresh-fruit cold chains by combining virtual cold chains with life cycle assessment. Applied Energy, 2019, Vol. 254, Art. 113586.

[4] Zhang C., Campana P.E., Liu C., Wang K., Yan J. Crowdfunding preferences for a sustainable milk product with integrated photovoltaic water pumping system in China. Applied Energy, 2019, Vol. 255, Art. 113694.

[5] Seck G.S., Guerassimoff G., Maïzi N. Heat recovery using heat pumps in non-energy intensive industry: are Energy Saving Certificates a solution for the food and drink industry in France? Applied Energy, 2015, Vol. 156, p. 374-389.

[6] Martins A.A., Araújo A.R., Graça A., Caetano N.S. Towards sustainable wine: Comparison of two Portuguese wines. Journal of Cleaner Production, 2018, Vol. 183, p. 662-676.

[7] Gilinsky A., Newton S.K., Vega R.F. Sustainability in the global wine industry: Concepts and cases. Agricultural and Agricultural Science Procedia, 2016, Vol. 8, p. 37-49.

[8] Merli R., Preziosi M., Acampora A. Sustainability experiences in the wine sector: toward the development of an international indicators system. Journal of Cleaner Production, 2018, Vol. 172, p. 3791-3805.

[9] Flores S.S. What is sustainability in the wine world? A cross-country analysis of wine sustaianbility frameworks. Journal of cleaner production, 2018, Vol. 172, p. 2301-2312.

[10] Cholette S., Venkat K. The energy and carbon intesity of wine distribution: a study of logistical options for delivering wine to consumers. Journal of Cleaner production, 2009, Vol. 17, p. 1401-1413.

[11]Filho M.G., Lumi M., Hasan C., Marder M., Leite L.C.S., Konrad O. Energy recovery from wine sector wastes: A study about the biogas generation potential in a vineyard from Rio Grande do Sul, Brazil. Sustainable Energy Technologies and Assessments, 2018, Vol. 29, p. 44-49. 
[12]Fernández-Puratinch H., Hernández D., Tenreiro C. Analysis of energetic performance of vine biomass residues as an alternative fuel for Chilean wine industry. Renewable Energy, 2015, Vol. 83, p. 1260-1267.

[13]Toscano G., Riva G., Duca D., Foppa Pedretti E., Corinaldesi F., Rossini G. Analysis of the characteristics of the residues of the wine production chain finalized to their industrial and energy recovery. Biomass and Bioenergy, 2013, Vol. 55, p. 260-267.

[14]Bacenetti J. Heat and cold production for winemaking using pruning residues: Environmental impact assessment. Applied Energy, 2019, Vol. 252, Art. 113464.

[15]Fuentes-Pila J., García J.L. Energy analysis of processes in Wineries-Handbook. Available online at url: http://www.teslaproject.org/ (accessed on March $\left.8^{\text {th }}, 2019\right)$.

[16] Smyth M., Nesbitt A. Energy and English wine production: A review of energy use and benchmarking. Energy for Sustainable Development, 2014, Vol. 23, p. 85-91.

[17]Botner M. How Reducing Energy Use Impacts the Bottom Line in the Winery and the Vineyard. Orchard \& Vine Magazine, 2016, available online at url: http://www.orchardandvine.net/articles/how-reducing-energy-use-impacts-the-bottom-line (accessed on March 13 ${ }^{\text {st }}$, 2019).

[18] Madison Gas and Electric. Managing Energy Costs in Wineries. Available online at url: https://www.mge.com/saving-energy/business/bea/article_detail.htm?nid=\%202607 (accessed on February $\left.27^{\text {th }}, 2019\right)$.

[19] Vela R., Mazarrón F.R., Fuentes-Pila J., Baptista F., Silva L.L., García J.L. Improved energy efficiency in wineries using data from audits. Ciência e Técnica Vitivinícola, 2017, Vol. 32, p. 62-71.

[20] Malvoni M., Congedo P.M., Laforgia D. Analysis of energy consumption: a case study of an Italian winery. Energy Procedia, 2017, Vol. 126, p. 227-233.

[21]Garn J. Benefits of energy auditing for your winery. Practical Winery \& Vineyard Journal, 2005, Vol. 3 (May-June).

[22] Galitsky C., Worrel E., Radspieler A., Healy P., Zechiel S. Best Winery Guidebook: Benchmarking and Energy and Water Savings Tool for the Wine Industry. Available online at url: $\quad$ https://www.energy.ca.gov/2005publications/CEC-500-2005-167/CDROM FOR PCs/BEST\%20Winery\%20Guidebook.pdf (accessed on March $2^{\text {nd }}, 2019$ )

[23] Gómez-Lorente D., Rabaza O., Aznar-Dols F., Mercado-Vargas M.J. Economic and Environmental Study of Wineries Powered by Grid-Connected Photovoltaic Systems in Spain. Energies, 2017, Vol. 10, p. 222.

[24]Jia T., Dai Y., Wang R. Refining energy sources in winemaking industry by using solar energy as alternatives for fossil fuels: A review and perspective. Renewable and Sustainable Energy Reviews, 2018, Vol. 88, p. 278-296.

[25]Carroquino J., Roda V., Mustata R., Yago J., Valiño L., Lozano A. et al. Combined production of electricity and hydrogen from solar energy and its use in the wine sector. Renewable Energy, 2018, Vol. 122, p. 251-263.

[26] García-Casarejos N., Gargallo P., Carroquino J. Attitude survey of wine sector toward renewables for reducing GHG. Energy Procedia, 2018, Vol. 153, p. 438-443.

[27] Genc M., Genc S., Goksungur Y. Exergy analysis of wine production: Red wine production process as a case study. Applied Thermal Engineering, 2017, Vol. 117, p. 511-521. 
[28] Celorrio R., Martínez E., Saenz-Díez J.C., Jiménez E., Blanco J. Methodology to decrease the energy demands in wine production using cold pre-fermentation. Computers and Electronics in Agriculture, 2015, Vol. 117, p. 177-185.

[29]Celorrio R., García J.L., Martínez E., Jiménez E., Blanco J. Methodology for the reduction of energy demand during cold stabilisation in the wine industry. Energy and Buildings, 2017, Vol. 142, p. 31-38.

[30]Huang S., Zuo W., Sohn M.D. Amelioration of the cooling load based chiller sequencing control. Applied Energy, 2016, Vol. 168, p. 204-215.

[31]Wang Y., Jin Y., Shi W., Wang J. Online chiller loading strategy based on the near-optimal performance map for energy conservation. Applied Energy, 2019, Vol. 238, p. 1444-1451.

[32] Schenk C., Schulz V., Rosch A., von Wallbrunn C. Less cooling energy in wine fermentation A case study in mathematical modeling, simulation and optimization. Food and Bioproducts Processing, 2017, Vol. 103, p. 131-138.

[33] Mazarrón F.R., Cid-Falceto J., Cañas I. An assessment of using ground thermal inertia as passive thermal technique in the wine industry around the world. Applied Thermal Engineering, 2012, Vol. 33-34, p. 54-61.

[34]Zhu K., Li X., Campana P.E., Li H., Yan J. Techno-economic feasibility of itnegrating energy storage systems in refrigerated warehouses. Applied Energy, 2018, Vol. 216, p. 348-357.

[35]Li S.-F., Liu Z.-H., Wang X.-J. A comprehensive review on positive cold energy storage technologies and applications in air conditioning with phase change materials. Applied Energy, 2019, Vol. 255, Art. 113667.

[36] Mađerić D., Pavković B., Lenić K. An experimental researchon energy efficiency of a beverage cooler with the latent heat storage. Applied Thermal Engineering, 2019, Vol. 148, p. 270-277.

[37] Guerrini L., Angeloni G., Baldi F., Parenti A. Thermal effects of pump-overs during red wine fermentation. Applied Thermal Engineering, 2017, Vol. 112, p. 621-626.

[38] Hyman B., Ozalp N., Varbanov P.S., Van Fan Y. Modeling energy flows in industry: General methodology to develop process step models. Energy Conversion and Management, 2019, Vol. 181, p. 528-543.

[39] Cho J., Kim Y. Improving energy efficiency of dedicated cooling systems and its contribution towards meeting an energy-optimized data center. Applied Energy, 2016, Vol. 165, p. 967-982.

[40] Termolog EPIX 10, produced by Logical Soft, available at url: https://termolog.logical.it/

[41] IMST-Group Instituto de Ingeniería Energética Universidad Politécnica de Valencia, 2019. Advanced Refrigeration Technologies Software IMST-ART Release 3.90.www.imstart.com.

[42] Melgaço de Oliveira C.C., Pereira Brittes J.L., Silveira Junior V. Dynamic operating conditions strategy for water hybrid cooling under variable heating demand. Applied Energy, 2019, Vol. 237, p. 635-645. 